\title{
Epigenetic Regulation in Plants
}

\section{Craig S. Pikaard ${ }^{1}$ and Ortrun Mittelsten Scheid ${ }^{2}$}

${ }^{1}$ Department of Biology, Department of Molecular and Cellular Biochemistry, and Howard Hughes Medical Institute, Indiana University, Bloomington, Indiana $47405 ;{ }^{2}$ Gregor Mendel-Institute of Molecular Plant Biology, Austrian Academy of Sciences, 1030 Vienna, Austria

Correspondence: ortrun.mittelsten_scheid@gmi.oeaw.ac.at

\section{SUMMARY}

The study of epigenetics in plants has a long and rich history, from initial descriptions of non-Mendelian gene behaviors to seminal discoveries of chromatin-modifying proteins and RNAs that mediate gene silencing in most eukaryotes, including humans. Genetic screens in the model plant Arabidopsis have been particularly rewarding, identifying more than 130 epigenetic regulators thus far. The diversity of epigenetic pathways in plants is remarkable, presumably contributing to the phenotypic plasticity of plant postembryonic development and the ability to survive and reproduce in unpredictable environments.

\section{Outline}

1 Plants as models for epigenetic research

2 Molecular components of chromatin in plants

\section{Molecular components of RNA- mediated gene silencing pathways}

4 Outlook

References

Editors: C. David Allis, Marie-Laure Caparros, Thomas Jenuwein, and Danny Reinberg

Additional Perspectives on Epigenetics available at www.cshperspectives.org

Copyright (C 2014 Cold Spring Harbor Laboratory Press; all rights reserved; doi: 10.1101/cshperspect.a019315

Cite this article as Cold Spring Harb Perspect Biol 2014;6:a019315 


\section{OVERVIEW}

Plants are masters of epigenetic regulation. All of the major epigenetic mechanisms known to occur in eukaryotes are used by plants, with the responsible pathways elaborated to a degree that is unsurpassed in other taxa. DNA methylation occurs in $\mathrm{CG}, \mathrm{CHG}$, and $\mathrm{CHH}$ sequence contexts in plant genomes, in patterns that reflect a balance between enzyme activities that install, maintain, or remove methylation. As in other eukaryotes, histone-modifying enzymes influence epigenetic states in plants and these enzymes are encoded by comparatively large gene families, allowing for diversified as well as overlapping functions. RNA-mediated gene silencing is accomplished using multiple distinct pathways to combat viruses, tame transposons, orchestrate development, and help organize the genome. The interplay between DNA methylation, histone modification, and noncoding RNAs provides plants with a multilayered and robust epigenetic circuitry.

The prominence of epigenetic regulation in plants reflects their mode of development, lifestyle, and evolutionary history. Unlike growth in mammals, in which organ and tissue formation is largely specified during embryonic development, plants grow by continuously producing new organs from self-sustaining stem cell populations known as meristems. Consequently, postembryonic development in plants is a continuous process shaped by environmental influences resulting in a high degree of phenotypic plasticity. Because plants are unable to escape their surroundings, they are forced to cope with changeable and often unfavorable growth conditions. Epigenetic regulatory mechanisms can facilitate metastable changes in gene activity and fine-tune gene expression patterns, thus enabling plants to survive and reproduce successfully in unpredictable environments. Polyploidization, an increase in the number of sets of chromosomes, is common in plants, amplifying gene families and fostering the functional specialization of duplicated genes, including those involved in epigenetic regulation.

Understanding the epigenetic regulatory machinery of plants has come, in large part, from genetic screens, most notably in Arabidopsis thaliana, a member of the mustard family that is highly amenable to genetic analyses and was the first plant species to have its genome sequenced. Crop plants, particularly maize, have also contributed substantially to the discovery of epigenetic phenomena and epigenetic regulatory mechanisms. The study of plant epigenetics and epigenomics has a long and rich history and, in synergy with parallel studies in animal and fungal systems, is contributing significantly to our basic understanding of epigenetic regulation. 


\section{PLANTS AS MODELS FOR EPIGENETIC RESEARCH}

\subsection{Overview}

Plant studies have provided numerous seminal contributions to the field of epigenetics. Among them is the distinction between euchromatin and heterochromatin based on cytological analyses (Heitz 1929). The observation in tomato and maize of heritable changes in a gene's expression state on exposure to an allele with an alternative state, a phenomenon known as paramutation, was early evidence for nonMendelian epigenetic inheritance (reviewed in ArteagaVazquez and Chandler 2010) and is now apparent in mammals and flies, as well as plants. Parental imprinting of individual genes, that is, the expression of a single allele of either maternal or paternal origin, which is a process whose misregulation is the basis for multiple genetic disorders in humans (see Zoghbi and Beaudet 2014), was first observed in maize (reviewed in Alleman and Doctor 2000). The repeated occurrence of individuals with altered flower symmetry, first described by Carl von Linné in the 18th century as "peloria" (monster) individuals, is now known to be caused by the formation of a silenced epiallele whose DNA sequence is identical to expressed alleles of the gene (Cubas et al. 1999). Epialleles can affect developmental switches; the FWA gene in Arabidopsis is an example in which silencing in some natural ecotypes (strains) delays flowering (Soppe et al. 2000). Cytogenetic analyses of metaphase chromosomes in plant hybrids in the 1930s showed that secondary constrictions and other cytogenetic characteristics were reproducibly altered in certain hybrid combinations. This differential production of secondary constrictions was later shown to be caused by the reproducible silencing of one parental set of ribosomal RNA (rRNA) genes, and the selective expression of the other parental set at these loci, an epigenetic phenomenon widespread among eukaryotes and known as nucleolar dominance (reviewed in Preuss and Pikaard 2007). Only the active rRNA genes gives rise to secondary constrictions, which are less condensed than flanking regions because of the persistent binding of RNA polymerase I transcription factors throughout the cell cycle. The pioneering work on transposable elements in maize by Barbara McClintock and others in the 1940s revealed numerous links between genetic behavior and epigenetic regulation (reviewed in Lisch 2009). Indeed, extant transposons and degenerate remains of transposons provide a means of establishing new regulatory elements and epigenetic modifications in eukaryotic genomes.

As transgenic technology in plants such as tobacco, petunia, and Arabidopsis became routine in the late 1980s, it became evident that transgene expression was unpredictable (reviewed in Wassenegger 2002; Matzke and Matzke
2004). This led to the realization that homology-dependent gene silencing can occur when transgenes bearing identical sequences to genes already present in the genome are introduced, with an enhanced messenger RNA (mRNA) turnover (posttranscriptional gene silencing, PTGS) or repression of transcription (transcriptional gene silencing, TGS) being the molecular basis for silencing. A striking example of PTGS, termed "cosuppression," occurred when overexpression of the gene encoding chalcone synthase $(C H S)$, a regulator of flower pigmentation, was attempted in petunia, this unexpectedly resulted in variegated or even completely white flowers rather than darker purple flowers. The lack of pigmentation in white sectors was because of coordinated gene silencing of both the CHS transgene and the endogenous CHS gene (reviewed in Jorgensen et al. 2006). PTGS is a form of RNA interference (RNAi), later discovered in Caenorhabditis elegans and other organisms (see Sec. 3).

By the mid-1990s, links between PTGS and virus resistance had been forged. Epigenetic mechanisms involving RNA molecules were shown to naturally protect plants from uncontrolled replication of viruses, which can be both inducers and targets of PTGS. It was soon realized that these mechanisms could be exploited to experimentally down-regulate plant genes by constructing viral vectors containing plant gene sequences, thus harnessing the virus-induced gene silencing pathway (VIGS, a topic discussed in more detail in Baulcombe and Dean 2014 and reviewed in Senthil-Kumar and Mysore 2011). Another mechanism discovered in viroid-infected plants is the RNA-guided specification of DNA methylation (RNA-directed DNA methylation, RdDM) and other heterochromatic marks at homologous DNA regions (Wassenegger et al. 1994). Transgene-induced RdDM is now widely used to methylate and transcriptionally silence promoters and is accomplished by intentionally generating doublestranded RNA (dsRNA) matching promoter sequences (see Sec. 3.4), a strategy that also works in animals (reviewed in Verdel et al. 2009).

Another pioneering contribution of plant epigenetic research was the application of deep sequencing to conduct genome-wide analyses (Zhang et al. 2006), including the first analysis of genomic methylation at single-base resolution (Cokus et al. 2008; Lister et al. 2008). These studies required the development of bioinformatics tools that have since been applied broadly for biomedical research.

\subsection{The Epigenomes of Plants and Mammals Are Similar}

Despite their obvious morphological differences and long evolutionary separation, the fundamental similarities be- 
tween animals and plants are remarkable. These similarities include many aspects of genome and epigenome organization, especially between plants and mammals. For instance, genome size, genome complexity, and the ratio of heterochromatin to euchromatin in seed plants are generally comparable to mammals. Also, plants and mammals make similar use of DNA methylation and histone posttranslational modifications (PTMs) for gene regulation. Overall, a comparison of genome organization and epigenetic regulation in different model systems reveals that there are more common features between plants and mammals than there are within the animal kingdom itself (Zhao and Garcia 2014). Consequently, epigenetic mechanisms discovered in plants or mammals are generally relevant to both systems.

\subsection{Unique Aspects of Plant Development Relevant to Epigenetic Regulation}

In considering the similarities and differences between plants and mammals, it is important to consider the special life histories of plants. In mammals, fertilization is achieved by fusion of two haploid cells that are direct products of the preceding meiosis. In contrast, plants have a haploid (gametophyte) growth stage that follows meiosis and precedes fertilization (Fig. 1). The male and female gametophytes are the pollen and embryo sac, respectively, each composed of multiple cells that are produced by mitotic divisions of the initial haploid meiotic products. In haploid gametophytes, which are genetically and metabolically active, loss of genetic or epigenetic information cannot be compensated for by information on homologous chromosomes; hence, deleterious mutations in essential genes are selected against. Unlike mammals, there is no evidence for a massive erasure of epigenetic marks during plant gametogenesis. Instead, repressive epigenetic marks in plant sperm and egg cells appear to be reinforced by specific trans-silencing RNAs produced in neighboring nuclei. This might explain how epigenetic changes are often transmissible through meiosis in plants.

Another distinctive feature of plants relative to animals is the lack of a defined germline set aside early in embryogenesis. Instead, germ cells are produced late in plant development after stem cells in the shoot undergo a transition from producing progenitor cells of vegetative organs to producing daughter cells that give rise to the floral organs in which meiosis and gametogenesis occur (Fig. 1). Thus, epigenetic modifications acquired by meristem cells in response to the plant's interactions with its environment have the potential to be conveyed to the germ cells.

In addition to the clusters of stem cells at the apex of the shoot and root, known as apical meristems, plants have lateral meristems. These include the stem cells that give rise to new xylem and phloem each year in perennials, resulting in the characteristic growth rings of tree trunks, as well as buds that are located at the base of each leaf and that can sprout to form vegetative organs or flowers. Many plants also have specialized organs, such as underground rhizomes, tubers, or bulbs that have stem cells capable of giving rise to shoots that form independent, new plants. These mechanisms of vegetative or clonal propagation are common in plants and are often more successful than seed dissemination as a strategy for colonizing a favorable location. Importantly, mitotically transmissible epigenetic states can be perpetuated among clones resulting from vegetative propagation.

In tissue culture, some differentiated plant somatic cells can be reprogrammed to form somatic embryos that develop into plants without a requirement for fertilization. As a result, cloning via somatic embryogenesis is routine for many plant species. However, among what should be genetically uniform clones, a surprising amount of phenotypic variability is observed. This so-called "somaclonal variation" has a strong epigenetic basis and is potentially useful for plant breeding and selection of adaptive traits (reviewed in Miguel and Marum 2011).

Another plant-specific feature is the existence of plasmodesmata, which are cytoplasmatic connections between cells allowing metabolites, proteins, RNAs, and even viruses to pass. Plant shoots can be cut and grafted as scions onto genetically different rootstocks (Fig. 1). This results in chimeras in which roots and shoots are genetically different. Diffusible epigenetic signals move through plasmodesmata and the vascular system and can be transmitted between roots to shoots in grafted plants (see Sec. 3.6.2 and Dunoyer et al. 2013). In this way, the epigenetic state of stem cells and gametes can potentially be modified by signals emanating from distant organs of the plant.

Plants have a high tolerance for polyploidy (the multiplication of whole chromosome complements) compared with mammals. In fact, most flowering plants have undergone polyploidization at least once in their evolutionary histories. Polyploid crops include wheat, cotton, potato, peanut, sugarcane, coffee, canola, and tobacco. The prevalence of polyploidy in plants suggests that it offers certain fitness advantages, such as built-in hybrid vigor or resistance to the effects of deleterious mutations, thereby allowing duplicated genes to potentially acquire beneficial mutations. The formation of polyploids is often associated with significant genomic and epigenetic changes (reviewed in Jackson and Chen 2010). Some of these changes occur within one or a few generations and can contribute to rapid adaptation and evolution in plants. Even diploid plants contain polyploid cells as a result of endoreplication, 


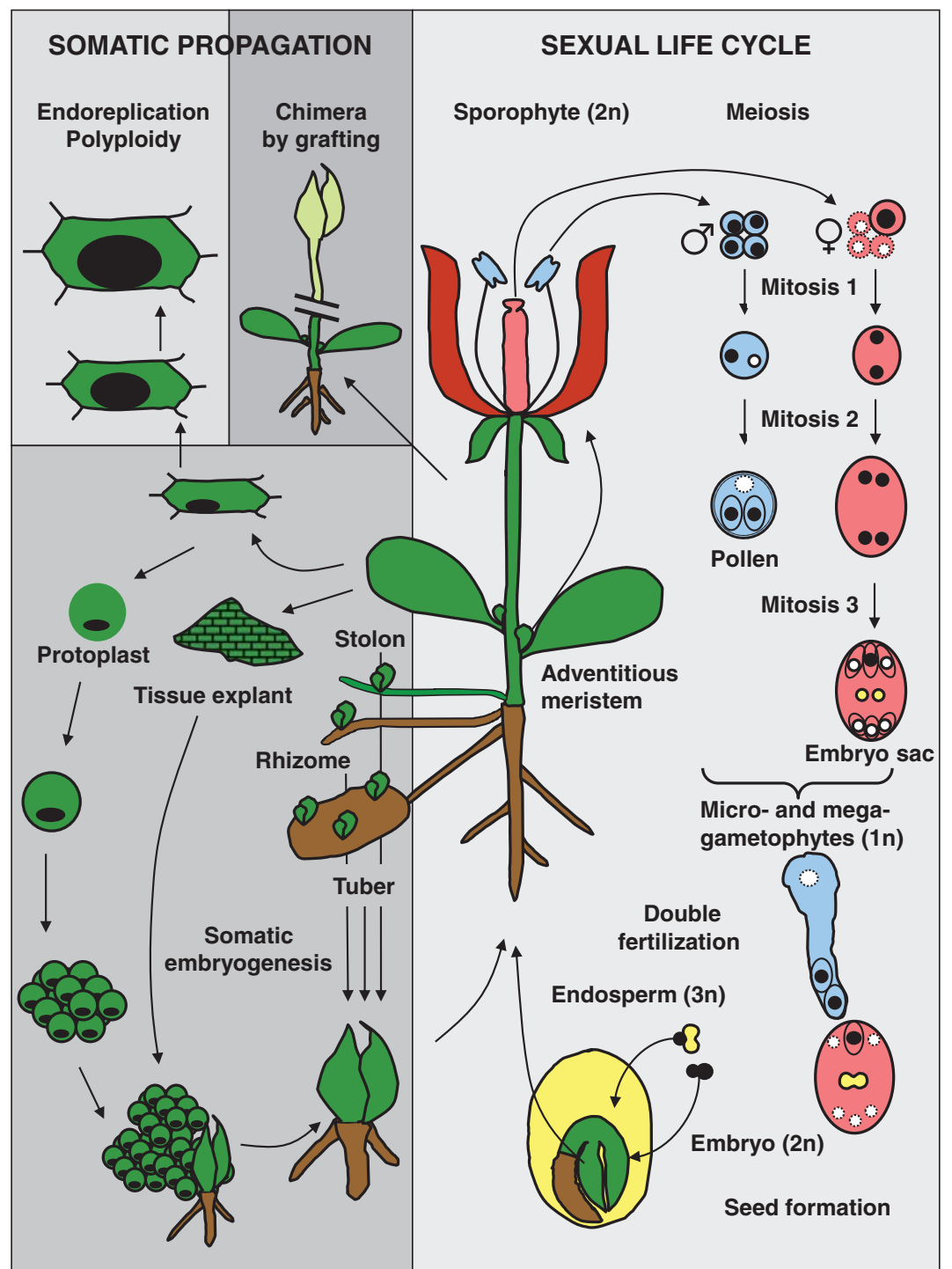

Figure 1. Unique aspects of the plant life cycle. Plants can propagate sexually (gametogenesis, fertilization, and seed formation; right) as well as somatically (vegetative explants, cell de- and re-differentiation, or somatic embryogenesis; left). The body of higher plants with roots, stem, leaves, and flowers is the diploid sporophyte. During meiosis, the chromosome number is reduced by half. Whereas in animals the meiotic products become the gametes without further division and fuse directly to produce the diploid embryo, plants form haploid male or female gametophytes via two or three mitotic divisions to form pollen or embryo sacs, respectively. The pollen grain ultimately contains one vegetative (white) and two generative (black) nuclei. The two generative nuclei fertilize the egg cell (black) and the central cell, the latter having a diploid nucleus derived from fusion of the two polar nuclei (yellow). This double fertilization gives rise to a diploid embryo and a triploid endosperm, the latter providing a nutrient source for the developing embryo. After seed germination, the embryo will grow into a new sporophyte. Most plants also have the potential for vegetative propagation through activation of lateral meristems, outgrowth of specialized organs (tubers, rhizomes or stolons), amplification in tissue culture, or regeneration from individual somatic cells after removal of the cell wall ( protoplasts). Endoreduplication is frequent in plants, producing polyploid cells or tissues. Plants can be grafted to produce chimeras. 
with endopolyploidy common in cells of the leaf, seed, and other plant organs. By contrast, endopolyploidy in mammalian cells is less common, but does occur, for instance, in muscle and liver cells.

\subsection{Genetic Attributes of Plants as Model Systems for Epigenetics}

Plants can be efficiently mutagenized by chemical or physical (e.g., radiation) treatments, random insertion of transgenes, or mobilization of transposable elements. Moreover, in plants that self-pollinate, such as A. thaliana, homozygous mutants can be easily identified among the thousands of progeny from a single mutagenized plant, without the need for laborious outcrossing or backcrossing procedures. Screens for mutations in epigenetic regulators are typically based on the recovery of expression of silenced marker genes, which are generally engineered transgenes. The ability to easily generate transgenic plants has thus greatly benefitted epigenetic research. In addition to such forward genetic approaches, reverse genetic approaches that ablate gene function are also possible. This has been facilitated by insertion mutants or the use of transgene-induced RNAi to knockout or knockdown the expression of candidate genes, such as genes homologous to epigenetic regulators identified in other organisms (Table 1).

Gene families encoding epigenetic modifiers can differ significantly in the number of family members between plants and mammals. In many cases, having large families of plant chromatin-modifying activities results in partial functional redundancies such that mutations in individual family members are less severe than in mammals. This can be useful if complete loss of function is lethal, thereby making mutants unavailable for study.

Nonessential genes in pathways that determine coloration of plant tissues have proven useful for identifying mutants affecting their epigenetic control (Fig. 2A-E). Other epigenetic modifier mutants cause morphological defects that are often tolerated in plants without lethal consequences (Fig. 2F). Thousands of individual plants can be screened for changes in the expression of endogenous or transgenic traits (Fig. 2G). Once specific epigenetic mutants are characterized, suppressor screens are often successful for identifying interacting components or alternative pathways, a strategy that has also been used in Drosophila (Elgin and Reuter 2013) and mouse (Blewitt and Whitelaw 2013).

A. thaliana has emerged as a leading model system for plant epigenetics research because of the availability of comprehensive collections of insertion mutations in nearly every gene, facile mutagenesis, extensive natural variation, complete genome sequence information for numerous accessions, and a wealth of genome-wide expression and chromatin-modification data. Arabidopsis is thus the focus of this article, and Table 1 summarizes the epigenetic modifiers for which functional information is available. This information has been obtained through a combination of forward- and reverse-genetic screens, biochemical assays, or homologies with known epigenetic modifiers in other systems. For more detailed information about individual genes in Arabidopsis, the reader is referred to TAIR, The Arabidopsis Information Resource (http://www.arabidop sis.org).

\section{MOLECULAR COMPONENTS OF CHROMATIN IN PLANTS}

More than 130 genes encoding proteins involved in epigenetic regulation in plants have been identified (Table 1). The epigenetic modifiers known to date can roughly be sorted into five groups according to their proven or presumptive functions, as discussed in Sections 2.1-2.4 and 3. This list is clearly incomplete, as new activities continue to be identified in ongoing research, but provides a framework for understanding plant epigenetics.

\subsection{Regulators of DNA Modification}

5-Methylcytosine $(5 \mathrm{mC})$ is a hallmark of epigenetic gene silencing and heterochromatin in both plants and mammals (the latter of which is discussed in Li and Zhang 2014; see also Zhao and Garcia 2014; reviewed in Furner and Matzke 2011; Meyer 2011). Whereas in nuclei of differentiated mammalian cells $5 \mathrm{mC}$ is found nearly exclusively at CG sites (often referred to as CpG sites), plants methylate cytosines within $\mathrm{CG}, \mathrm{CHG}$, or $\mathrm{CHH}$ motifs (in which $\mathrm{H}$ is A, T, or C). Mammalian promoters are often present within methylation-free CG-rich regions known as $\mathrm{CpG}$ islands, but $\mathrm{CpG}$ islands are not easily distinguishable in plants. Nevertheless, cytosine methylation is nonrandomly distributed in plants, occurring primarily in repetitive regions of the genome that are enriched in transposable elements, centromeric repeats, or arrays of silent $5 \mathrm{~S}$ or $45 \mathrm{~S}$ rRNA gene repeats. Cytosine methylation also occurs at some differentially regulated promoters and within the protein-coding regions of highly expressed genes (Zilberman et al. 2007). The latter gene body methylation is evolutionarily conserved, occurring in animal species as diverse as humans and honeybees (Feng et al. 2010). The significance of gene body CG methylation is not yet clear, but its enrichment within exons suggests a potential role in pre-mRNA splicing. 
Table 1. Components of epigenetic regulation in the model plant species Arabidopsis thaliana

\begin{tabular}{|c|c|c|}
\hline $\begin{array}{l}\text { Gene or mutant } \\
\text { acronym }^{\mathrm{a}}\end{array}$ & Gene or mutant name & Confirmed or putative function of protein \\
\hline \multicolumn{3}{|l|}{ DNA modification } \\
\hline CMT3 & Chromomethyltransferase & DNA methyltransferase (mainly $\mathrm{CHG}$ and $\mathrm{CHH}$ ) \\
\hline$D M E$ & Demeter & $\begin{array}{l}\text { DNA glycosylase-domain protein, cytosine } \\
\text { demethylation }\end{array}$ \\
\hline$D M L 2,3$ & Demeter-like proteins & $\begin{array}{l}\text { DNA glycosylase-domain protein, cytosine } \\
\text { demethylation }\end{array}$ \\
\hline DNMT2 & DNA methyltransferase & Interaction with $\mathrm{HD} 2$ \\
\hline DRM1 & Domains-rearranged methyltransferase & DNA methyltransferase (CG, $\mathrm{CHG}$, and $\mathrm{CHH}$ ) \\
\hline DRM2 & Domains-rearranged methyltransferase & $\begin{array}{l}\text { Major de novo DNA methyltransferase } \\
\text { (CG, } \mathrm{CHG} \text {, and } \mathrm{CHH})\end{array}$ \\
\hline HOG1 & Homology-dependent gene silencing & $S$-adenosyl-L-homocysteine hydrolase \\
\hline MBD10 & Methylcytosine-binding domain protein & Methylcytosine-binding protein \\
\hline MBD6 & Methylcytosine-binding domain protein & Methylcytosine-binding protein \\
\hline MET1, DDM2 & Methyltransferase, decreased DNA methylation & DNA methyltransferase (mainly CG) \\
\hline ROS1 & Repressor of silencing & $\begin{array}{l}\text { DNA glycosylase-domain protein, cytosine } \\
\text { demethylation }\end{array}$ \\
\hline ROS3 & Repressor of silencing & $\begin{array}{l}\text { DNA glycosylase-domain protein, cytosine } \\
\text { demethylation }\end{array}$ \\
\hline VIM1,-2,-3 & Variant in methylation & Methylcytosine-binding proteins \\
\hline$Z D P$ & Zinc finger DNA 3'-phosphoesterase & 3'-Phosphatase \\
\hline \multicolumn{3}{|l|}{ Histone modification } \\
\hline ATX1 & Arabidopsis homolog of trithorax & Histone methyltransferase \\
\hline ATXR3/SDG2 & Arabidopsis homolog of trithorax, SET domain group & Histone methyltransferase \\
\hline ATXR5,-6,-7 & Arabidopsis trithorax-related proteins & Histone methyltransferase (ATXR5,-6: H3K27me1) \\
\hline EFS/SDG8/ASHH2 & $\begin{array}{l}\text { Early flowering in short days, SET domain group, ASH1 } \\
\text { homolog }\end{array}$ & Histone methyltransferase \\
\hline ELF6 & Early flowering & Histone demethylase (H3K4me1,-2,-3) \\
\hline$F L D, L D L 1,-2$ & Flowering locus D, LDS1-like & Histone demethylases \\
\hline$H A C 1,-5,-12$ & Histone acetyltransferase CBP-like & Histone acetyltransferase \\
\hline HAG1-,2 & Histone acetyltransferase GCN5-like & Histone acetyltransferase (H3K14ac) \\
\hline$H A M 1,-2$ & Histone acetyltransferase Myst-like & Histone acetyltransferase \\
\hline $\begin{array}{l}\text { HD2a-d; HDT1, } \\
\quad-2,-3,-4\end{array}$ & Histone deacetylase & Atypical histone deacetylase \\
\hline HDA1 & Histone deacetylase & Histone deacetylase \\
\hline $\begin{array}{l}\text { HDA6, SIL1, AXE1 } \\
\quad \text { RTS1 }\end{array}$ & $\begin{array}{l}\text { Histone deacetylase, modifier of silencing, auxin-gene } \\
\text { repression, RNA-mediated transcriptional silencing }\end{array}$ & Histone deacetylase \\
\hline$H U B 1,-2$ & E3 ubiquitin ligase & $\mathrm{H} 2 \mathrm{~B}$ monoubiquitination \\
\hline IBM1 & Increase in bonsai methylation & Histone demethylase \\
\hline JMJ14 & Arabidopsis thaliana jumonji & Histone demethylase (H3K4me1,-2,-3) \\
\hline MEE27 & Maternal effect embryo arrest & Histone demethylase \\
\hline OTLD1 & Otubain-like deubiquitinase & $\mathrm{H} 2 \mathrm{~B}$ deubiquitination \\
\hline REF6 & Relative of early flowering & Histone demethylase \\
\hline SUP32/UBP26 & Suppressor of ros, ubiquitin protease & $\mathrm{H} 2 \mathrm{~B}$ deubiquitination \\
\hline SUVH2 & $\mathrm{Su}(\operatorname{Var}) 3-9$ homolog & H3K9 methyltransferase \\
\hline SUVH4, KYP1 & Su(Var)3-9 homolog, kryptonite & H3K9 methyltransferase \\
\hline SUVH5,-6 & $\mathrm{Su}(\operatorname{Var}) 3-9$ homolog & Recognition of DNA methylation (SUVH5) \\
\hline$U B C 1,-2$ & E2 ubiquitin-conjugating enzyme & $\mathrm{H} 2 \mathrm{~B}$ monoubiquitination \\
\hline ULT1 & Ultrapetala & Regulator of histone methylation, ATX1 interactor \\
\hline \multicolumn{3}{|c|}{ Polycomb-group proteins and interacting components } \\
\hline AtBMII $a,-b,-c$ & B cell-specific Mo-MLV integration site 1 & PRC1 subunit \\
\hline AtCYP71 & Cyclophilin & LHP1 and H3 interaction \\
\hline AtRING1 $a,-b$ & RING finger protein & PRC1 subunit \\
\hline$C L F$ & Curly leaf & Polycomb-group protein $(\mathrm{E}(\mathrm{z}))$ \\
\hline CUL4 & Cullin protein & Subunit of E3 ligase complex, MSI1 interactor \\
\hline
\end{tabular}




\section{C.S. Pikaard and O. Mittelsten Scheid}

Table 1. Continued

\begin{tabular}{|c|c|c|}
\hline $\begin{array}{l}\text { Gene or mutant } \\
\text { acronym }^{\text {a }}\end{array}$ & Gene or mutant name & Confirmed or putative function of protein \\
\hline$D D B 1$ & Damaged DNA-binding & Subunit of E3 ligase complex, MSI1 interactor \\
\hline EMF2 & Embryonic flower & Polycomb-group protein $(\mathrm{Su}(\mathrm{z}) 12)$ \\
\hline FIE, FIS3 & $\begin{array}{l}\text { Fertilization-independent endosperm, fertilization- } \\
\text { independent seeds }\end{array}$ & Polycomb-group protein (Esc) \\
\hline FIS2 & Fertilization-independent seeds & Polycomb-group proteins $(\mathrm{Su}(\mathrm{z}) 12)$ \\
\hline LHP1/TFL2 & Like heterochromatin protein, terminal flower & PRC1 subunit, formation of repressive chromatin \\
\hline LIF2 & LHP1-interacting factor & RNA processing, LHP1 interaction \\
\hline MEA, FIS1 & Medea, fertilization-independent seeds & Polycomb-group protein $(\mathrm{E}(\mathrm{z}))$ \\
\hline MSI1 & Multicopy suppressor of IRA homolog & Polycomb-group protein ( p55) \\
\hline MSI4/FVE & Multicopy suppressor of IRA homolog & $\begin{array}{l}\text { Polycomb-group protein ( } \mathrm{p} 55) \text {, Cul4-DDB1 and } \\
\text { PCR2 interactor }\end{array}$ \\
\hline MSI5 & Multicopy suppressor of IRA homolog & $\begin{array}{l}\text { Polycomb-group protein ( } \mathrm{p} 55) \text {, interactor of HDA6, } \\
\text { FLC silencing }\end{array}$ \\
\hline$R B R$ & Retinoblastoma-related protein & PRC2 regulator during development \\
\hline SWN & Swinger & Polycomb-group protein $(\mathrm{E}(\mathrm{z}))$ \\
\hline VEL1 & Vernalization-like & Homeodomain protein \\
\hline VIL2 & Vin3-like & Homeodomain protein \\
\hline VIN3 & Vernalization-insensitive & Homeodomain protein \\
\hline VRN2 & Vernalization & Polycomb-group protein $(\mathrm{Su}(\mathrm{z}) 12)$ \\
\hline VRN5 & Vernalization & Homeodomain protein \\
\hline \multicolumn{3}{|c|}{ Chromatin formation or chromatin remodeling } \\
\hline$A R P 4,-5$ & Actin-related protein & Subunits of INO80 complex \\
\hline AtASF1a,-b & Arabidopsis antisilencing factor & Histone chaperone $\mathrm{H} 3 / \mathrm{H} 4$ \\
\hline AtCHR12 & Arabidopsis chromatin remodeling & SNF2/Brahma-type protein \\
\hline AtNAP1 1-4 & Arabidopsis nucleosome assembly protein & Histone chaperone $\mathrm{H} 2 \mathrm{~A} / \mathrm{H} 2 \mathrm{~B}$ \\
\hline AtSWI3 A-D & Arabidopsis homolog of SWI3 & $\begin{array}{l}\text { Subunits of SWITCH/SUCROSE } \\
\text { NONFERMENTABLE (SWI/SNF)-remodeling } \\
\text { complexes }\end{array}$ \\
\hline AtSWP73 A,B & Arabidopsis homolog of SWP73 & Subunit of SWI/SNF-remodeling complex \\
\hline$B R M$ & Brahma & SWI2/SNF2 ATPase family protein \\
\hline BRU1/MGO3/TSK & Brushy, Mgoun, Tonsoku & Uncharacterized protein \\
\hline $\mathrm{BSH}$ & Bushy & Subunit of SWI/SNF-remodeling complexes \\
\hline CHR11 & Chromatin-remodeling protein & ISWI-like chromatin remodeling protein \\
\hline CLSY1 & Classy & SWI2/SNF2 family ATPase \\
\hline$D D M 1, S O M$ & Decreased DNA methylation, somniferous & SWI2/SNF2 family ATPase \\
\hline DMS3/IDN1 & Defective in meristem silencing, involved in de novo & $\begin{array}{l}\text { Structural-maintenance-of-chromosomes protein; } \\
\text { required for RNA Pol V transcription }\end{array}$ \\
\hline DMS11 & Defective in meristem silencing & GHKL ATPase, interaction with DMS3 \\
\hline DRD1 & Defective in RNA-directed DNA methylation & $\begin{array}{l}\text { SWI2/SNF2 ATPase; required for RNA Pol V } \\
\text { transcription }\end{array}$ \\
\hline FAS1 & Fasciated & Chromatin assembly factor subunit $\mathrm{H} 3 / \mathrm{H} 4$ \\
\hline FAS2 & Fasciated & Chromatin assembly factor subunit $\mathrm{H} 3 / \mathrm{H} 4$ \\
\hline HIRA & Histone regulator A & Histone chaperone $\mathrm{H} 3 / \mathrm{H} 4$ \\
\hline INO80 & Inositol-requiring & Subunits of INO80 complex \\
\hline MGO1 & Mgoun & DNA topoisomerase \\
\hline MOM1 & Morpheus' molecule & Genetic interaction with RNA Pol V \\
\hline MSI1 & Multicopy suppressor of IRA homolog & Chromatin assembly factor subunit, $\mathrm{H} 3 / \mathrm{H} 4$ \\
\hline$N R P 1,-2$ & NAP (nucleosome assembly protein)-related protein & Histone chaperone $\mathrm{H} 2 \mathrm{~A} / \mathrm{H} 2 \mathrm{~B}$ \\
\hline PIE & Photoperiod-independent early flowering & ATPase subunit of SWR1 \\
\hline$P K L$ & Pickle & CHD3 chromatin remodeling factor \\
\hline RPA2 & Replication protein A & Single-stranded DNA-binding protein \\
\hline SEF/SWC6 & Serrated and early flowering, SWR 1 complex & Subunit of SWR1 \\
\hline$S P D$ & Splayed & SWI2/SNF2 family ATPase \\
\hline SPT16 & Suppressor of Ty insertion-like & Histone chaperone $\mathrm{H} 2 \mathrm{~A} / \mathrm{H} 2 \mathrm{~B}$ \\
\hline
\end{tabular}


Table 1. Continued

\begin{tabular}{|c|c|c|}
\hline $\begin{array}{l}\text { Gene or mutant } \\
\text { acronym }^{\text {a }}\end{array}$ & Gene or mutant name & Confirmed or putative function of protein \\
\hline SSRP1 & Structure-specific recognition protein & $\begin{array}{l}\text { High mobility group (HMG) protein, histone } \\
\text { chaperone subunit }\end{array}$ \\
\hline SUF3/ESD1/ARP6 & Suppressor of Frigida, early in short days, actin-related protein & Subunit of SWR2, H2A.Z deposition \\
\hline TSL & Tousled & Phosphorylation of ASF1 \\
\hline \multicolumn{3}{|l|}{ RNA silencing } \\
\hline$A B H 1 / C B P 80$ & ABA-hypersensitive, cap-binding complex & microRNAs (miRNA) processing \\
\hline AGO1 & Argonaute & PAZ-PIWI domain protein, translational repression \\
\hline$A G O 10, \mathrm{PNH} / Z L L$ & Argonaute, Pinhead, Zwille & PAZ-PIWI domain protein, translational repression \\
\hline AGO4 & Argonaute & PAZ-PIWI domain protein, siRNA-binding \\
\hline AGO6 & Argonaute & PAZ-PIWI domain protein, siRNA-binding \\
\hline AGO7, ZIP & Argonaute, Zippy & PAZ-PIWI domain protein \\
\hline AGO9 & Argonaute & $\begin{array}{l}\text { PAZ-PIWI domain protein, female gametophyte } \\
\text { formation, siRNA binding }\end{array}$ \\
\hline AtNUC-l1 & Nucleolin-like & rRNA gene regulation \\
\hline $\begin{array}{l}\text { DCL1, CAF1, SIN1, } \\
\quad \text { EMB76, SUS1 }\end{array}$ & $\begin{array}{l}\text { Dicer-like, Carpel factory, short integuments, embryo- } \\
\text { defective, suspensor }\end{array}$ & RNase III (dsRNase), miRNA and siRNA generation \\
\hline DCL2 & Dicer-like & RNase III (dsRNase), siRNA generation \\
\hline DCL3 & Dicer-like & RNase III (dsRNase), siRNA generation \\
\hline$D C L 4, S M D$ & Dicer-like & RNase III (dsRNase), siRNA generation \\
\hline$D D L$ & Dawdle & FHA domain protein, miRNA processing \\
\hline$D R B 1$ & Double-stranded RNA-binding protein & Dicer 1-interacting protein, miRNA strand selection \\
\hline$D R B 2,-3,-4$ & Double-stranded RNA-binding protein & Dicer-interacting proteins, siRNA processing \\
\hline ESD7 & Early in short days & Subunit of DNA polymerase epsilon \\
\hline$F C A$ & Flowering time & RRM-domain protein \\
\hline FDM1-5 & Factor of DNA methylation & dsRNA-binding protein (FDM1) \\
\hline FPA & Flowering time & RRM-domain protein \\
\hline FRY1 & Fiery & Nucleotidase \\
\hline HEN1 & HUA enhancer & dsRNA-binding, RNA methyltransferase \\
\hline HST & Hasty & miRNA export receptor \\
\hline HYL1 & Hyponastic leaves & Nuclear dsRNA-binding protein \\
\hline IDN2/RDM12 & Involved in de novo, RNA-directed DNA methylation & dsRNA-binding protein \\
\hline KTF1/RDM3/SPT5-l & $\begin{array}{l}\text { KOW domain-containing transcription factor, suppressor of } \\
\text { Ty insertion-like }\end{array}$ & Part of RdDM effector complex \\
\hline$N R P(A / B / C / D) 5$ & Nuclear RNA polymerases I, II, III, IV & 5th subunit common to Pols I-IV \\
\hline$N R P(B / D / E) 3 a,-3 b$ & Nuclear RNA polymerases II, IV, and V & Alternative 3rd subunits of Pols II, IV, or V \\
\hline$N R P(B / D / E) 9 a,-9 b$ & Nuclear RNA polymerases II, IV, and V & Alternative 9th subunits of Pols II, IV, and V \\
\hline$N R P(D / E) 2, D R D 2$ & $\begin{array}{l}\text { Nuclear RNA polymerases IV and V; defective in RNA-directed } \\
\text { DNA methylation } 2\end{array}$ & 2nd subunit of Pol IV and PolV \\
\hline$N R P(D / E) 4$ & Nuclear RNA polymerases IV and V & 4th subunit of RNA Pol IV and RNA Pol V \\
\hline$N R P(D / E) 5 b$ & Nuclear RNA Pol IV and V & $\begin{array}{l}\text { Alternative 5th subunit of RNA Pol IV (and RNA Pol V } \\
\text { likely) }\end{array}$ \\
\hline NRPD 1, SDE4 & Nuclear RNA polymerase IV, silencing defective 4 & Pol IV largest subunit \\
\hline NRPD7a & Nuclear RNA Pol IV & Major 7th subunit of RNA Pol IV \\
\hline NRPE1, DRD3 & $\begin{array}{l}\text { Nuclear RNA Pol V, defective in RNA-directed DNA } \\
\text { methylation }\end{array}$ & RNA Pol V largest subunit \\
\hline NRPE5 & Nuclear RNA Pol V & 5th subunit of RNA Pol V \\
\hline NRPE7/NRPD7b & Nuclear RNA Pol V & $\begin{array}{l}\text { Major 7th subunit of RNA Pol V; alternative seventh } \\
\text { subunit of RNA Pol IV }\end{array}$ \\
\hline$R D M 1$ & RNA-directed DNA methylation & $\begin{array}{l}\text { Component of DDR complex required for RNA Pol V } \\
\text { transcription }\end{array}$ \\
\hline RDM12 & RNA-directed DNA methylation & Coiled-coil protein \\
\hline RDM4/DMS4 & $\begin{array}{l}\text { RNA-directed DNA methylation, defective in meristem } \\
\text { silencing }\end{array}$ & $\begin{array}{l}\text { IWR1-like regulator of multisubunit RNA polymerase } \\
\text { assembly }\end{array}$ \\
\hline$R D R 1$ & RNA-dependent RNA polymerase & RNA-dependent RNA polymerase \\
\hline
\end{tabular}


Table 1. Continued

\begin{tabular}{|c|c|c|}
\hline $\begin{array}{l}\text { Gene or mutant } \\
\text { acronym }^{\mathrm{a}}\end{array}$ & Gene or mutant name & Confirmed or putative function of protein \\
\hline$R D R 2$ & RNA-dependent RNA polymerase & RNA-dependent RNA polymerase \\
\hline RDR6, SDE1, SGS2 & $\begin{array}{l}\text { RNA-dependent RNA polymerase, silencing defective, } \\
\text { suppressor of gene silencing }\end{array}$ & RNA-dependent RNA polymerase \\
\hline$S D E 3,-5$ & Silencing-defective & RNA helicase \\
\hline$S E$ & Serrate & Zn finger protein, miRNA processing \\
\hline SGS3 & Suppressor of gene silencing & Coiled-coil protein \\
\hline SHH1/DTF1 & $\begin{array}{l}\text { Sawadee homeodomain homolog, DNA-binding transcription } \\
\text { factor }\end{array}$ & Homeodomain protein \\
\hline SR45 & Arginine/serine-rich & Splicing factor \\
\hline WEX & Werner syndrome-like exonuclease & RNase D exonuclease \\
\hline$X R N 2,-3$ & XRN homolog & Exoribonuclease \\
\hline XRN4/EIN5 & XRN homolog, ethylene insensitive & Exoribonuclease, small RNA processing \\
\hline
\end{tabular}

${ }^{a}$ Different acronyms in row one refer to the same gene.

\subsubsection{DNA Methyltransferases}

DNA methyltransferases catalyze cytosine methylation de novo at previously unmethylated cytosines or maintain preexisting cytosine methylation patterns (illustrated in Fig. 2 in Li and Zhang 2014). In plants, de novo methylation is directed by small interfering RNAs (siRNAs) and occurs on cytosines present within CG, CHG, or $\mathrm{CHH}$ motifs (see Sec. 3.5). Maintenance methylation perpetuates preexisting methylation patterns, especially at CG or CHG motifs, which are known as symmetrical sites because each DNA strand reads CG or CHG in the $5^{\prime}$ to $3^{\prime}$ direction. This symmetry provides a basis for cytosine methylation patterns on mother strands to be imparted to daughter strands after each round of DNA replication. Maintenance methylation also occurs following DNA repair, allowing newly synthesized DNA to be methylated based on the methylation pattern of the nonrepaired strand.

Three families of DNA methyltransferase are conserved among eukaryotes and are present in plants: homologs of mammalian Dnmt1, Dnmt2, and Dmnt3 (Fig. 4 in Li and Zhang 2014). DNA METHYLTRANSFERASE 1 (MET1), the plant homolog of mammalian Dnmt1, is the major CG maintenance methyltransferase and may also contribute to CG de novo methylation. DNMT2 homologs are also present in plants and possess transfer RNA (tRNA) methylase activity, like mammalian DNMT2 (Goll et al. 2006); however, no catalytic activity on DNA has been observed for these enzymes. The plant DOMAINS-REARRANGED METHYLTRANSFERASEs (DRM) and their mammalian homologs, the Dnmt3 group, are predominantly de novo methyltransferases. DRM proteins have the domains of their amino- and carboxy-terminal halves arranged in reverse order when compared with Dnmt3 (domains VI$\mathrm{X}$ are followed by $\mathrm{I}-\mathrm{V}$ ). DRM2 catalyzes methylation of cytosines in all sequence contexts and is the prominent cytosine methyltransferase in the RNA-directed DNA methylation pathway (see Sec. 3.5.2).

Unlike mammals, plants have a unique family of cytosine methyltransferases wherein the defining characteristic is the presence of a chromodomain that binds to methylated histones. CHROMOMETHYLASE 3 (CMT3) is the enzyme primarily responsible for CHG maintenance methylation. CMT3's chromodomain binds histone $\mathrm{H} 3$ that is dimethylated on lysine 9 (H3K9me2). CHG methylation, in turn, provides a binding site for the SET- AND RINGASSOCIATED (SRA) domain of the H3K9 methyltransferase SUVH4, leading to H3K9 dimethylation. Thus, CMT3 and SUVH4 constitute a self-reinforcing loop in which repressive DNA methylation and histone modification marks specify one another to maintain an epigenetic state (reviewed in Law and Jacobsen 2010). CHROMOMETHYLASE 2 (CMT2) plays a role in maintaining $\mathrm{CHH}$ methylation in specific genomic contexts, such as the central regions of large transposable elements, presumably via cross talk with histone modifications like its paralog, CMT3 (Zemach et al. 2013).

In contrast to mammals in which dnmt 1 and dnmt3 mutants die during embryonic development, or shortly after birth, met1, cmt2, cmt3, and drm mutants are viable, even in combination with one another. As a result, the role of DNA methylation in a variety of processes can be studied in plants, including vegetative and reproductive development, gametogenesis, fertilization, and the cross talk between DNA methylation and histone modification (as in the case of CMT3 described in the previous paragraph; reviewed in Furner and Matzke 2011; Meyer 2011). 

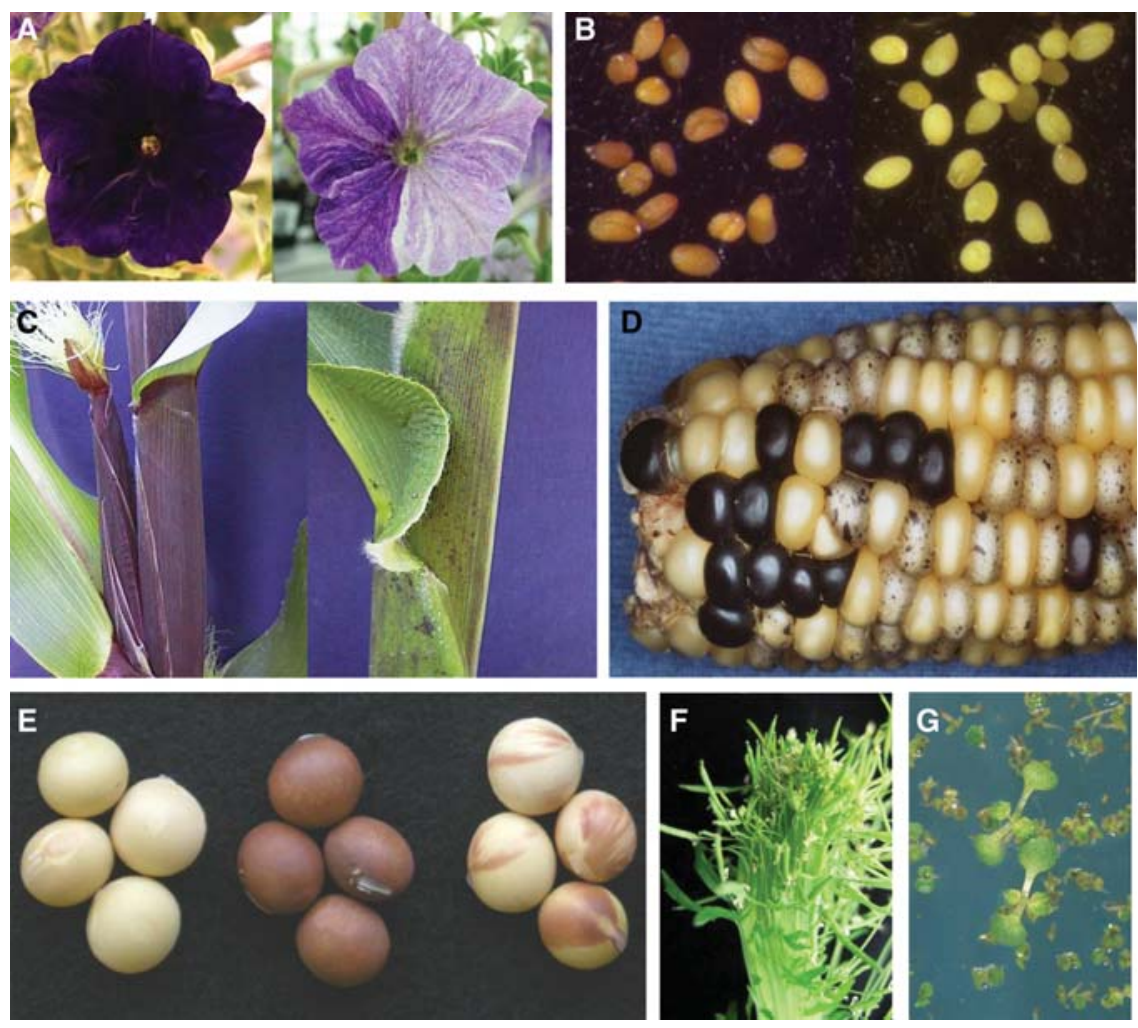

Figure 2. Assays for epigenetic control in plants. Genes determining coloration of plant tissue allow easy and inexpensive gene expression readout in vivo. (A) Expression of the dihydroflavonol reductase (DFR) gene is required for dark purple petunia flowers, whereas silencing of the DFR promoter gives rise to variegated, light coloration. (B) Seeds from Arabidopsis expressing the chalcone synthase (CHS) gene have dark seed coats, whereas silencing of CHS upon expression of a homologous transgene results in yellow seeds. $(C)$ Maize plants with the B-I gene have purple pigmentation, in contrast to green plants with a paramutagenic, inactive $\mathrm{B}^{\prime}$ allele whose DNA sequence is identical. (D) Maize ear, segregating a transposon insertion (Spm) in the B-Peru gene required for anthocyanin pigment. Purple kernels represent revertants in which the Spm element excised from the gene in the germline. The heavily spotted kernels contain the Spm element in the active form that induces frequent somatic excision sectors during kernel development. The kernels with rare, small purple sectors represent kernels in which the Spm element has been epigenetically silenced. (E) The dark color of soybeans (middle) is extinguished in cultivated varieties (left) because of natural posttranscriptional silencing of the CHS gene and can be partially reversed by infection of the parental plant with a virus possessing a PTGS suppressor protein, producing a mottled pattern (right). (F) Epigenetic regulation can become manifest also in plant morphology; reduced function of a chromatin assembly factor subunit leads to a "fasciated" Arabidopsis stem. $(G)$ Release of silencing from a transgenic resistance marker in Arabidopsis can be scored by growth on selective medium. (A, Courtesy of Jan Kooter; $B$, courtesy of Ian Furner; $C$, reprinted from Chandler et al. 2000, with kind permission from Springer Science and Business Media; D, courtesy of Vicki Chandler; E, reprinted, with permission, from Senda et al. 2004, (C) American Society of Plant Biologists.)

\subsubsection{Cytosine Demethylation and DNA Glycosylases}

In spite of mechanisms allowing DNA methylation to be maintained, cytosine methylation can be lost. Passive loss occurs when methylation fails to be maintained during replication or following DNA repair. Active demethylation can also occur via enzymatic activity. Active demethylation in animals was shown decades ago, but the exact players and mechanisms are still debated (reviewed in Gehring et al. 2009; Niehrs 2009). In Arabidopsis, active demethylation is catalyzed by REPRESSOR OF SILENCING 1 (ROS1), DEMETER (DME), or DEMETER-LIKE proteins (DML2,-3). These are large proteins that contain DNA glycosylase domains. ROS1 displays nicking activity on methylated DNA, resulting in the removal and replacement of methylated cytosines via a pathway related to base excision repair (Agius et al. 2006). The demethylation process requires the ZINC FINGER DNA 3'PHOSPHOESTERASE (ZDP), which is thought to remove the $3^{\prime}$ phosphate at the nick site, thereby generating a $3^{\prime}$ hydroxyl that allows DNA ligase to 
seal the gap (Martínez-Macías et al. 2012). ROS1 is expressed constitutively, potentially contributing to loss of DNA methylation in nondividing cells at all stages of development. ROS1 is thought to be guided to its sites of action by its association with ROS3, an RNA-binding protein, suggesting that RNA may play a role in guiding demethylation as well as in guiding de novo methylation in the RNA-directed DNA methylation pathway (Zheng et al. 2008). The DNA glycosylase DME is especially important in the gametophytes, where it helps erase $5 \mathrm{mC}$ patterns that otherwise silence a specific subset of genes (Choi et al. 2002; Schoft et al. 2011). Mutations eliminating the CG methyltransferase MET1 suppress $d m e$ mutants, suggesting that DME is required primarily for demethylation of CG dinucleotides (Xiao et al. 2003). The DME paralogs, DML2 and -3, affect cytosine methylation in CG, $\mathrm{CHG}$, and $\mathrm{CHH}$ contexts at specific genomic sites (Ortega-Galisteo et al. 2008).

Collectively, the functions of the multiple demethylating enzymes in Arabidopsis indicate that reversibility of DNA methylation is critical for the regulation of specific genes during development. There is also growing evidence that cytosine methylation can be rapidly lost in other ways (reviewed in Reinders and Paszkowski 2009). Spontaneous changes in cytosine methylation can occur sporadically among isogenic populations (Becker et al. 2011; Schmitz et al. 2011), thereby creating or derepressing epialleles that may influence fitness and natural selection (Roux et al. 2011).

\subsubsection{Methylcytosine-Binding Proteins}

METHYL-C-BINDING DOMAIN (MBD) proteins, which share sequence similarity with mammalian proteins such as $\mathrm{MeCP} 2$, are epigenetic "reader" modules thought to help transduce DNA methylation patterns into altered transcriptional activity (see Figs. 8 and 9 in Li and Zhang 2014). Plants have more MBD-containing genes (13 in Arabidopsis) than mammals. However, outside the conserved MBD domain, there is little homology with mammalian MBDs (Springer and Kaeppler 2005). Only three members of the Arabidopsis family are known to bind specifically to methylated DNA, and these are missing in monocotyledonous plants such as maize, wheat, and rice (reviewed in Grafi et al. 2007). Other protein domains also confer $5 \mathrm{mC}$ binding. For instance, the SRA domain of SUVH4 (an H3K9 methyltransferase) binds to methylated CHG sites providing a mechanistic link between repressive histone and DNA modifications as mentioned in Section 2.1.1. Likewise, the SRA domains of VIM proteins (orthologs of UHRF1 in mammals) bind to hemimethylated DNA and recruit MET1/DNMT1 to modify the new daughter strand following replication (Woo et al. 2007, 2008).

\subsubsection{Proteins Required for Methyl Group Donor Synthesis}

Most methylating enzymes require the cofactor $S$-adenosyl-methionine (SAM, or AdoMet) as the methyl group donor. A key enzyme in SAM biosynthesis, S-ADENOSYL-L-HOMOCYSTEINE HYDROLASE, regulates SAM levels by removing substrate inhibition. Mutations in the Arabidopsis gene encoding this enzyme result in decreased DNA methylation and release of transcriptional silencing, especially from genes in pericentromeric heterochromatin (Rocha et al. 2005; Jordan et al. 2007). The mutations also affect histone methylation, further impacting epigenetic regulation (Baubec et al. 2010).

\subsection{Histone-Modifying Enzymes and Histone Variants}

As in other organisms, plants contain several histone variants and enzymes that posttranslationally modify histones and influence gene regulation. Application of chromatin immunoprecipitation followed by deep sequencing has given insight into the genome-wide distribution of histone variants and histones bearing different posttranslational modifications (reviewed in Roudier et al. 2009), including the coincidence or mutual exclusion of specific chromatin marks (Roudier et al. 2011). Histone-modifying enzymes are often encoded by large gene families in plants (reviewed in Berr et al. 2011; Deal and Henikoff 2011; Lauria and Rossi 2011).

\subsubsection{Histone Deacetylases and Histone Acetyltransferases}

Histone acetylation is an epigenetic mark generally associated with active chromatin and transcription, whereas transcriptionally nonactive sequences usually lack acetylation. The functions of histone acetyltransferase (abbreviated to HAT) "writer" activities can be reversed by histone deacetylase (HDAC) "eraser" enzymes that allow for the reversibility of acetylation as an epigenetic mark. The structure and function of these genes is extensively discussed in Marmorstein and Zhou (2014) and Seto and Yoshida (2014). Plants have multiple gene family members for both HATs and HDACs (Pandey et al. 2002; Chen and Tian 2007). The members of the HAT family can be classified into five different subfamilies based on their structure and different substrate specificities (Earley et al. 2007). The GCN5-homolog, HAG1, for instance specifically methylates H3K14, 
as in yeast and mammals, and regulates several developmental processes in Arabidopsis (reviewed in Servet et al. 2010). We currently know of plant homologs to three of the five HAT subfamilies (see Table 1). Plants also have homologs of the histone deacetylases that are highly conserved throughout all eukaryotes, catalyzing the removal of histone acetylation to generate more repressive chromatin. There is a plant-specific family of putative histone deacetylases, named the HD2 or HDT family, which is implicated in gene silencing, but definitive HDAC activity has not yet been shown for recombinant HDT proteins. Genetic screens have so far identified only two HDACs that function as epigenetic regulators: HDA1 and HDA6 (Table 1). HDA6 plays a role in maintaining CG and CHG methylation, interacting with the DNA methyltransferase MET1, and is involved in transgene and transposon silencing, rRNA gene repression, and nucleolar dominance. Although deficiency mutants have only subtle morphological defects, HDA6 is involved in seed maturation, flowering time control, and stress responses (reviewed in Aufsatz et al. 2007; Kim et al. 2012). Pleiotropic morphological changes are apparent on reduced expression and/or overexpression of HDA1 and HD2A/HDT1, but their functions are not clear. Dissection of HAT and HDAC function is somewhat complicated by their redundancy and their potential operation in the context of large multiprotein complexes.

\subsubsection{Histone Methyltransferases and Histone Demethylases}

Like acetylation, histone methylation is a potentially reversible mark. Histone lysine methyltransferases (HKMTs) installing this modification are usually characterized by the presence of a SET domain (SU(VAR)/E(Z)/TRX; discussed extensively in Cheng 2014). Depending on the specific histone lysine that is methylated, HKMTs can promote or inhibit transcription. Some SET domain proteins are members of the Polycomb group (PcG) or trithorax group (TrxG) that maintain transcriptionally repressed or active states, respectively, of specific genes during plant and animal development (see Sec. 2.3 and Grossniklaus and Paro 2014). Other SET domain proteins of the Su(var)3-9 family participate in maintaining condensed heterochromatin, silencing transposons, or controlling DNA replication.

The Arabidopsis genome encodes 49 SET domain proteins, grouped into four conserved families: $\mathrm{E}(\mathrm{Z}), \mathrm{ASH} 1$, TRX, and SU(VAR)3-9-related proteins (Pontvianne et al. 2010). The latter and largest group is mostly, but not exclusively, responsible for H3K9 methylation. KRYPTONITE/ SUPPRESSOR OF VARIEGATION 3-9 homolog 4 (KYP/ SUVH4) and SUVH2, -5, and -6 catalyze H3K9me1 and -me2 installation. As described for SUVH4, their SRA domain, which binds $5 \mathrm{mC}$, contributes to their cooperation with CMT3 to maintain CHG methylation and H3K9me2 at silenced loci. $\mathrm{H} 3 \mathrm{~K} 9 \mathrm{me} 3$ is likely accomplished by the more distantly related SUVR proteins, and in contrast to animals in which it is a prominent heterochromatic mark, in plants it is found at expressed euchromatic genes. The TRX family member ARABIDOPSIS TRITHORAX 1 (ATX1) activates floral homeotic genes, presumably by means of its ability to catalyze histone H3 lysine 4 (H3K4) methylation. ATXR5 and ATXR6 monomethylate H3K27, a mark of repressed heterochromatin. Overreplication of heterochromatin occurs in atxr5 atxr6 double mutants, pointing to a role in replication control (Jacob et al. 2010). Mutants lacking ATXR3 have reduced $\mathrm{H} 3 \mathrm{~K} 4 \mathrm{me} 2 / 3$ and severe developmental defects, partly because of reduced cell size. ASH 1 HOMOLOG 2 (ASHH2), a member of the ASH1 group, catalyzes $\mathrm{H} 3 \mathrm{~K} 36 \mathrm{me} 2 / 3$, thereby reinforcing active chromatin marks at target loci, including several pathogen resistance genes. Genes of the $\mathrm{E}(\mathrm{z})$ group are relevant to Polycomb regulation (as discussed in Sec. 2.3).

There are two classes of proteins that can demethylate histone tails at different positions. The lysine-specific histone demethylase-LIKE (LDL) proteins act via amine oxidation, and the JUMONJI-C-DOMAIN (JmjC) proteins act via hydroxylation (discussed extensively in Cheng 2014 see also Shi and Tsukada 2013). Arabidopsis has four LDL and $21 \mathrm{JmjC}$ genes in several subgroups (reviewed in Chen and Tian 2007; Liu et al. 2010). The LDL proteins and some JmjC proteins are involved in flowering time control, have specific target genes, and can act in cooperation with transcription factors. The JmjC protein, INCREASE IN BONSAI METHYLATION (IBM1), counteracts H3K9 methylation and CHG DNA methylation. Developmental defects due to loss of IBM1 are consequently suppressed in double mutations with suvh4 and cmt3. Several enzymes potentially changing histone methylation marks are still uncharacterized, and antagonism or cooperativity, as well as target specificity are likely to result in a complex pattern of writing and reading these marks.

\subsubsection{Enzymes for Other Histone Modifications}

One of the other important histone PTMs, in addition to acetylation and methylation, is phosphorylation (reviewed in Houben et al. 2007). Histone phosphorylation is involved in DNA repair ( $\gamma \mathrm{H} 2 \mathrm{AX})$ and the regulation of chromosome segregation and cell division (Aurora kinases). Histone phosphorylation can be influenced by other epigenetic histone marks, as is the case for phosphorylation of $\mathrm{H} 3 \mathrm{~S} 10$, which is influenced by the modification state of the adjacent lysine, H3K9. ADP-ribosylation of histones occurs 
in plants, but has not been studied extensively. Ubiquitination of histones $\mathrm{H} 2 \mathrm{~A}$ and/or H2B also has important regulatory functions in animals and plants (reviewed in Berr et al. 2011; Bycroft 2011) and can recruit or exclude other modifying enzymes. Proteins that install or remove ubiquitination have been characterized and influence cell cycle, development, and pathogen resistance.

\subsubsection{Histone Variants, Linker Histones, and Nonhistone Proteins}

Histones are among the most conserved proteins across eukaryotic taxa and are encoded by highly redundant gene families. Like animals, plants have developed structurally and functionally distinct classes of $\mathrm{H} 2 \mathrm{~A}$ and $\mathrm{H} 3$ histone variants (discussed in Henikoff and Smith 2014). The physical properties of the variants play an important role in their dynamic association with DNA (reviewed in Ingouff and Berger 2010; Deal and Henikoff 2011).

Phosphorylation of the H2AX variant marks the sites of DNA damage and is believed to recruit DNA repair proteins. H2A.Z is a variant found mainly around the transcriptional start site of genes, likely regulating transcription, and is mutually exclusive with DNA methylation (Zilberman et al. 2008). Its incorporation requires the activity of a SWR1 chromatin-remodeling complex. On heat stress, H2A.Z-containing nucleosomes dissociate from the DNA, accompanied by changes in gene expression (Kumar and Wigge 2010). The CenH3 variant of histone $\mathrm{H} 3$ specifies the nucleosomes of centromeric regions and is required for kinetochore assembly, microtubule attachment, and chromosome segregation during cell division. Histone variant $\mathrm{H} 3.3$, which differs from the canonical $\mathrm{H} 3$ subunit at only a few amino acids, is found predominantly at regulatory regions and expressed genes. It is incorporated into chromatin in a replication-independent manner, involving special chaperones and remodeling complexes. However, the mechanisms responsible for histone variant replacement outside of replication are not well understood in plants.

In addition to the four histones that form nucleosome core particles, the compaction of DNA and its accessibility to interacting proteins is also determined by linker histones, particularly histone H1. Linker histones display substantial diversity, and their functional specialization is suggested by the expression of stress-inducible variants. Down-regulating specific linker histones is sometimes compensated for by the up-regulation of other variants, but can also result in DNA hypomethylation and pleiotropic phenotypic defects (reviewed in Jerzmanowski 2007).

As in other eukaryotes, plants have nonhistone chromosomal proteins that may contribute to epigenetic regulation, including HMG proteins. The best characterized and most diverse subgroup of these proteins in plants is the HMGB family, whose members differ in expression level, pattern, localization, and interaction with DNA and other proteins. Mutation and ectopic expression of individual family members indicate their partial subfunctionalization and a role in development and stress response (reviewed in Pedersen and Grasser 2010). One HMG protein, STRUCTURE-SPECIFIC RECOGNITION PROTEIN (SSRP1), is indirectly involved in DNA demethylation of imprinted genes in the central cell of the female gametophyte (Ikeda et al. 2011).

Cohesin complexes secure sister chromatid alignment before their separation during mitotic and meiotic anaphase, and are also involved in DNA repair, spindle attachment, chromosome condensation, and regulation of DNA accessibility. Cohesin structure, assembly, and removal appear to be highly conserved, but some family members in plants may have specialized functions (reviewed in Yuan et al. 2011). For instance, DEFECTIVE IN MERISTEM SILENCING3/INVOLVED IN DE NOVO (DMS3/IDN1) is a protein related to the hinge domain region of cohesins and condensins and is necessary for DNA-dependent RNA polymerase V (RNA Pol V) transcription in the establishment of RdDM (see Sec. 3.5.2).

Proteins such as REPLICATION PROTEIN A2 (RPA2) or REPLICATION FACTOR C1 have been identified in mutant screens for epigenetic regulators (Elmayan et al. 2005; Kapoor et al. 2005). Enhanced phenotypes of chromatin mutants when combined with loss-of-function mutants of the topoisomerase homolog MGOUN (MGO) also indicate a role for this protein, especially in connection with stem cell and meristem maintenance (Graf et al. 2010). It can be expected that many other nonhistone proteins interacting with DNA will also turn out to be direct or indirect epigenetic regulators.

\subsection{Polycomb Proteins and Interacting Components}

PcG group proteins were initially identified as master regulators and suppressors of homeotic genes in Drosophila. In balance with the activating TrxG proteins, PcGs determine cell proliferation and cell identity (see PcG proteins in Grossniklaus and Paro 2014 and TrxG proteins in Kingston and Tamkun 2014).

POLYCOMB REPRESSIVE COMPLEX 2 (PRC2) in plants is the more conserved of two different types of PcG complexes and is responsible for trimethylation of histone $\mathrm{H} 3$ at lysine 27 (H3K27me3), as in animals. Each subunit in the Drosophila PRC2 complex has several paralogous equivalents in Arabidopsis (see Fig. 3 in Grossniklaus 
and Paro 2014). MEDEA (MEA), CURLY LEAF (CLF), and SWINGER (SWN) corresponding to the Drosophila protein $\mathrm{E}(\mathrm{Z})$; FERTILIZATION-INDEPENDENT SEEDS 2 (FIS2), VERNALIZATION 2 (VRN2), and EMBRYONIC FLOWER 2 (EMF2) corresponding to $\mathrm{Su}(\mathrm{z}) 12$; FERTILIZATION-INDEPENDENT ENDOSPERM (FIE) corresponding to Esc; and MULTICOPY SUPPRESSOR OF IRA HOMOLOG 1-5 corresponding to p55 (reviewed in Koehler and Hennig 2010). This diversification of PRC2 component proteins is thought to be associated with the evolutionary expansion of land plants (reviewed in Butenko and Ohad 2011). Plant PRC2 components are required at different developmental stages and function at specific, but sometimes overlapping, subsets of genes. For many functions, plant PRC2 interacts with additional proteins or specific RNA transcripts, as in the control of flowering time (discussed in Baulcombe and Dean 2014). PcG proteins themselves are under strict regulatory control, in part via DNA demethylation. At least two PcG genes (MEA and FIS2) are imprinted genes, meaning that they are differentially expressed depending on the parent from which they were inherited (reviewed in Raissig et al. 2011). Although imprinting evolved independently in plants and mammals (Table 1), DNA methylation and PcG proteins are key components in both cases.

PRC1, the other PcG protein complex, is more dissimilar in Arabidopsis compared with animals, but has related functions. Like the Drosophila protein POLYCOMB, the Arabidopsis-LIKE HETEROCHROMATIN PROTEIN 1 (LHP1) binds to H3K27me3 and might "read" and "translate" this modification into additional and more repressive chromatin configurations, such as by interaction with the H2A ubiquitinating enzymes, AtRING 1, -2, and AtBMI1, also homologs of PRC1 components.

Subunits of both PRC core complexes interact with other proteins that could modulate specificity, but the means by which PcG complexes are recruited to specific target genes in plants is still not clear. Importantly, the consensus sequences for Polycomb or Trithorax responsive elements determined in animals have not been identified in plants.

\subsection{Nucleosome-Organizing Proteins}

Replication, transcription, recombination, and repair require transient or lasting changes in the positioning of nucleosomes and their association with DNA. Therefore, dynamic processes at the chromatin level are not restricted to reversible DNA or protein modifications, but can include changes in nucleosome occupancy, nucleosome composition, and the accessibility of the DNA to other proteins.

\subsubsection{Chromatin-Remodeling Complexes}

Relocation or dissociation of nucleosomes can be accomplished by chromatin-remodeling ATPases such as the SWI/SNF complex first identified in yeast and named according to the processes affected in the mutants (see Becker and Workman 2013). Plants have several such complexes (reviewed in Jerzmanowski 2007). Genetic screens have provided functional information for only a handful of putative chromatin remodelers, the first identified being DECREASE IN DNA METHYLATION 1 (DDM1).

Loss-of-DDM1-function results in genome-wide reduction of DNA methylation and H3K9me2, transcriptional activation of repetitive elements, and dysregulation of numerous genes. As a result, $d d m 1$ mutants display severe developmental and morphological defects that increase in severity with successive generations. The gradual reduced fitness of $d d m 1$ mutants is attributable to the accumulation of epimutations and insertional mutations caused by reactivated transposons. Part of the epigenetic information, in the form of DNA methylation, is irreversibly lost in $d d m 1$ mutants, yet backcrosses with wild-type plants can restore the pattern of modification at some loci as a result of de novo methylation (Teixeira et al. 2009). Like the SWI2/SNF2 ATPase protein, DDM1 displays ATP-dependent nucleosome repositioning activity in vitro (Brzeski and Jerzmanowski 2003). The loss of cytosine methylation that occurs in $d d m 1$ mutants does not occur in mutants that lack both DDM1 and linker histone $\mathrm{H} 1$ (Zemach et al. 2013) indicating that DDM1 is needed for the maintenance methylation machinery to be able to access nucleosomal DNA that is highly packaged, involving both core and linker histones. DDM1's ortholog in mammals, LYMPHOID-SPECIFIC HELICASE, is similarly important for global CpG methylation and development.

Two members of the SWI2/SNF2 family in Arabidopsis, DEFECTIVE IN RNA-DIRECTED DNA METHYLATION 1 (DRD1) and CLASSY 1 (CLSY1) are unique to the plant kingdom and have specialized roles in RNA-directed DNA methylation (see Sec. 3.5.2). Four other SWI2/SNF2 proteins, BRAHMA (BRM), SPLAYED (SPD), and MINUSCULE 1 and 2, are involved in the control of similar, but not identical, subsets of genes involved in hormone responses and stem cell maintenance (Sang et al. 2012).

Besides the ATPases, other core subunits of SWI/SNF remodelers are represented in plants, including several SWI3 family members (AtSWI3 A-D), one SNF5 homolog (BSH), and two SWP73 homologs (reviewed in Jerzmanowski 2007). Their roles in plants have not been studied extensively, but SWI3 has been shown to interact with RNA binding proteins involved in RNA-directed DNA 
methylation and to influence the spacing of nucleosomes at silenced loci (Zhu et al. 2012).

Subunits of other remodeling complexes include CHROMATIN-REMODELING PROTEIN 11 (CHR11; an ISWI complex protein), PICKLE (PKL; a CHD3 complex protein), and INOSITOL-REQUIRING 80 and ACTINRELATED PROTEINS 4 AND 5 (INO80, ARP4, ARP5; INO80 complex proteins). Mutants defective for these activities are characterized by developmental abnormalities and impaired DNA repair.

MORPHEUS' MOLECULE 1 (MOM1) is a plant-specific epigenetic regulator that is related to SWI2/SNF2 by virtue of a homologous, but incomplete, ATPase domain and is also related to CHD3. The lack of mom1, unlike $d d m 1$ or $p k l$, does not result in morphological defects. Its exact mode of action is unknown, yet mom 1 mutants are characterized by having an intermediate chromatin state at target genes that partially overlap with those targeted by the RdDM pathway (reviewed in Habu 2010).

The SWR1 complex C plays an important epigenetic role in the deposition of H2A.Z at transcription start sites (and the antagonistic exclusion of DNA methylation. The Arabidopsis SWR1 complex includes the ATPase subunit PHOTOPERIOD-INDEPENDENT EARLY FLOWERING (PIE), SWR1 COMPLEX 6 (SWC6), and ACTIN-RELATED PROTEIN 6 (ARP6). How this complex is directed to specific target genes is not clear, but its function is essential for developmental decisions and stress responsiveness.

\subsubsection{Chromatin Assembly Factors}

Whereas SWI/SNF and other remodeling complexes act on nucleosomes that are already associated with DNA, other activities are required for assembling core histones into new nucleosomes after replication, reestablishing chromatin after repair or recombination-associated DNA synthesis, or for the exchange of histones in connection with transcriptional processes. These functions are exerted by histone chaperones, which are mostly acidic proteins that interact with each other and specific canonical, or variant, histones (see Almouzni and Cedar 2014 for more detail).

Plants have three chaperones for loading $\mathrm{H} 3 / \mathrm{H} 4$ tetramers and three for adding $\mathrm{H} 2 \mathrm{~A} / \mathrm{H} 2 \mathrm{~B}$ dimers (reviewed in Zhu et al. 2011b). The CHROMATIN ASSEMBLY FACTOR 1 (CAF-1) complex helps to bring $\mathrm{H} 3 / \mathrm{H} 4$ tetramers to the replication fork. Mutations in genes encoding the two larger CAF-1 subunits in Arabidopsis ( fas1, fas2) cause characteristic morphological anomalies (fasciation, Fig. 2F), deficiencies in DNA repair, reductions in rRNA gene copy numbers, and derepression of repetitive elements. This indicates that correct nucleosome deposition is essential for development, genome stability, and epigenetic control. As would be expected, the lack of CAF-1 subunits does not interfere with maintenance of DNA methylation, but it can lead to the erasure of other histone-based epigenetic marks. Reduced levels of the third CAF-1 component, MSI1, does not cause fasciation, but lead to distorted seed development and several morphological changes, probably caused by to its multiple roles, including a role within the PRC2 complex. There are two other $\mathrm{H} 3 / \mathrm{H} 4$ chaperones that function independently of replication, but also in cooperation with CAF-1: HISTONE REGULATOR A (HIRA), for which there is one Arabidopsis homolog and ANTISILENCING FUNCTION 1 (ASF1), which has two Arabidopsis homologs.

Histones $\mathrm{H} 2 \mathrm{~A}$ and $\mathrm{H} 2 \mathrm{~B}$ are assumed to be installed by NUCLEOSOME ASSEMBLY PROTEIN 1 (NAP1), NAP1RELATED PROTEIN (NRP), and FACILITATES CHROMATIN TRANSCRIPTION (FACT) proteins. In Arabidopsis, there are a number of homologs to these proteins: four NAP1, two NRP, and two FACT homologs, each displaying similarity to the yeast or animal counterparts (reviewed in Zhu et al. 2011b).

Some chaperone subunits can be regulated by posttranslational modification, as indicated by the phenotype of TOUSLED (TSL) mutants, which lack an ASF1 kinase. A mutant of the Arabidopsis protein named BRUSHY (BRU) has a similar phenotype to plant CAF-1 fas mutants- that is, sensitivity to DNA damage, interference with TGS, and developmental defects. Although BRU has no homology with any known histone chaperones, the additional dysregulation of PcG-controlled genes at specific genomic clusters, likely indicates BRU's importance for maintaining different epigenetic states (Ohno et al. 2011).

It is striking that most mutations in genes for histone chaperones affect the organization of the meristems, the maintenance of stem cells, or processes in the differentiation zone adjacent to the stem cell niche within the meristem. This might reflect the requirement for correct histone and nucleosome deposition to perpetuate stem cell identities in plants.

\section{MOLECULAR COMPONENTS OF RNA- MEDIATED GENE SILENCING PATHWAYS}

As discussed in the preceding sections, cytosine methylation and posttranslational histone modifications are important aspects of epigenetic gene regulation in plants, helping to establish or maintain gene "on" or "off" states at the level of transcription. Epigenetic regulation also occurs posttranscriptionally through targeted mRNA degradation or translational inhibition. This PTGS can thus act to control the temporal or spatial distribution of develop- 
mentally important mRNAs and serve as a potent defense against invaders that include viruses, microbial pathogens, and transgenes (Ruiz-Ferrer and Voinnet 2009; Vazquez et al. 2010).

A common feature of transcriptional and posttranscriptional silencing mechanisms in plants is the involvement of small RNAs, specifically miRNAs or siRNAs. The biogenesis of these small RNAs in plants shares similarities with their biogenesis in other eukaryotes, suggesting that RNA-based silencing mechanisms, involving mi- and siRNA, have a common ancient origin (Chapman and Carrington 2007; Shabalina and Koonin 2008). However, duplication and subfunctionalization of genes involved in miRNA- or siRNA-mediated processes in plants has led to the evolution of multiple pathways that are specialized to accomplish specific tasks (Herr 2005; Baulcombe 2006; Xie and Qi 2008; Chen 2009; Vazquez et al. 2010). These include (1) a pathway for the biogenesis of miRNAs that are complementary to target sequences, resulting in the downregulation of individual transcribed mRNAs (Sec. 3.2); (2) a pathway in which a miRNA initiates the production of secondary trans-acting siRNAs that down-regulate multiple targets with no complementarity to the initiating miRNA; (3) a pathway for siRNA-mediated degradation of invading viral RNAs or transgene RNAs (Sec. 3.4); and (4) a pathway for siRNA-mediated DNA methylation and transcriptional silencing of transposons, viruses, and specific genes (Sec. 3.5). Collectively, these pathways provide plants with an arsenal of RNA-mediated silencing capabilities that is unrivaled by other eukaryotes.

\subsection{Common Features of miRNA and siRNA Biogenesis and Silencing}

miRNAs and siRNAs share a number of common features in plants, as in other eukaryotes (Bartel 2004; Voinnet 2009; Axtell et al. 2011). Both are produced from dsRNA precursors by the action of RNaseIII-related Dicer (DCL) endonucleases. Resulting small RNAs are then incorporated into a multiprotein RNA-induced silencing complex (RISC) that has, at its core, a member of the Argonaute (AGO) protein family (Czech and Hannon 2011). The AGO protein binds the $3^{\prime}$ end of the small RNA via its PAZ domain and uses the small RNA to base-pair with complementary target RNAs (Joshua-Tor 2006). As a consequence, the target RNA can be cleaved by the AGO protein's PIWI domain, or translation can be blocked without cleavage of the associated RNA, or chromatin-modifying machinery can be recruited to transcriptionally silence the locus. The different outcomes depend on both the class of small RNA involved and the particular AGO protein partner (see also Martienssen and Moazed 2014).
The double-stranded precursors of miRNAs or siRNAs are generated in several ways. In the case of miRNAs, DNAdependent RNA polymerase II (RNA Pol II) transcripts with extensive self-complementarity fold back on themselves to form stem-loop structures with imperfect double-stranded stems that can be diced by DCL1 (Fig. 3). In the case of siRNAs, the double-stranded precursors can be generated via convergent, bidirectional transcription by a DNA-dependent RNA polymerase such as RNA Pol II, thereby generating transcripts that overlap and base-pair. Alternatively, RNA transcripts can be used as templates for an RNA-dependent RNA polymerase (RdRP), to generate a complementary strand.

Diversification of the core machinery responsible for siRNA biogenesis and function underlies the evolution of the different small RNA silencing pathways in plants (Vazquez et al. 2010; Xie and Qi 2008). Like fission yeast (S. pombe) and nematodes (C. elegans), but unlike mammals or Drosophila, plants make use of RNA-dependent RNA polymerases for the production of dsRNA. Six distinct RdRPs are encoded by the Arabidopsis genome. Likewise, Arabidopsis has four distinct Dicer endonucleases, DICER-LIKE (DCL) 1 through 4, whereas mammals, fission yeast, and nematodes have only one Dicer, and fruit flies have two. The plant Dicers generate small RNAs with different sizes: miRNAs of (mostly) $21 \mathrm{nt}$ (DCL1), or siRNAs that are $21 \mathrm{nt}$ (DCL4), $22 \mathrm{nt}$ (DCL2), or 23$24 \mathrm{nt}$ (DCL3). The different sized siRNAs have distinct, yet partially overlapping functions, based on their associations with a diversified AGO protein family that has 10 members in Arabidopsis (Vaucheret 2008). The different RdRPs, Dicers, and AGO proteins are used in a variety of permutations to accomplish diverse small RNA-mediated silencing phenomena.

\section{2 miRNA Biogenesis and Function}

miRNAs are critical for plant and animal development, helping limit the functions of complementary mRNAs to a specific subset of cells by bringing about their posttranscriptional degradation or translational repression in adjacent cells (Carrington and Ambros 2003; Ambros 2004; Bartel 2009; Cuperus et al. 2011). miRNAs silence gene expression by base-pairing to target mRNAs in the context of a multiprotein RISC complex, facilitating mRNA cleavage, referred to as "slicing," or the inhibition of mRNA translation (Fig. 3). The importance of miRNAs in plant development is underscored by the fact that many of the genes involved in miRNA biogenesis and function were initially identified in genetic screens for mutants affecting development. Developmental processes requiring miRNAs include stem cell maintenance and differentiation, 


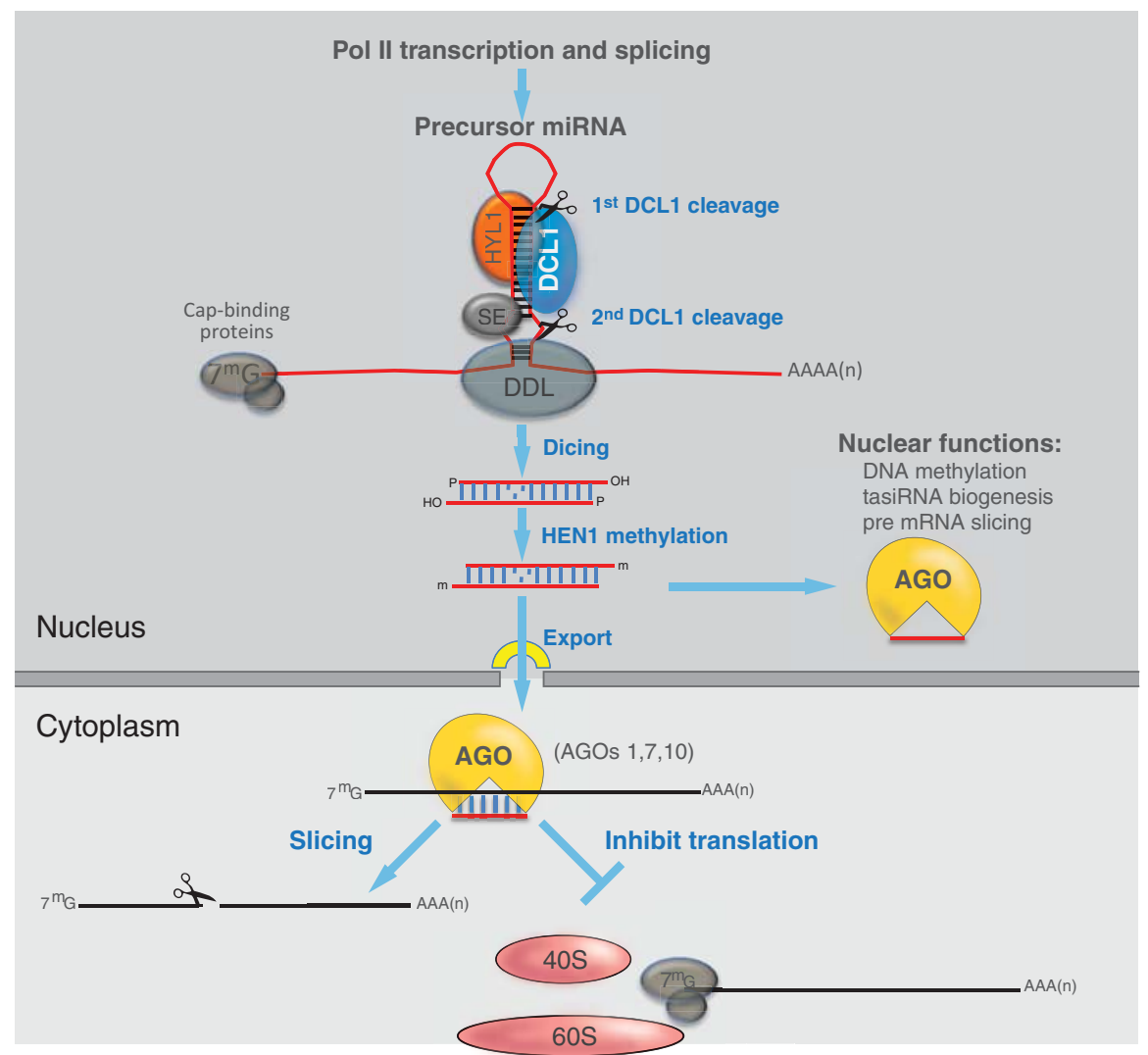

Figure 3. miRNA biogenesis and modes of action. Capped and polyadenylated transcripts of nuclear RNA Pol II that form imperfect hairpins serve as the precursors for miRNAs. DCL1 cleaves these precursors with the help of the HYL1, DDL1, and SE nucleic acid-binding proteins. Diced products are end-methylated by HEN1 and exported to the cytosplasm in a process involving the exportin 5 homolog, HST. In association with AGO1 or a related AGO protein, such as AGO10, the miRNA guides the cleavage or translational inhibition of complementary mRNAs. Nuclear functions in which miRNAs are implicated include specific cases of cytosine methylation, trans-acting siRNA (tasiRNA) production or pre-mRNA degradation.

specification of organ polarity, vascular development, floral patterning, hormone signaling, and responsiveness to environmental stresses (reviewed in Rubio-Somoza and Weigel 2011; Khraiwesh et al. 2012).

In plants, as in nematodes, loci encoding miRNAs were initially discovered as genes not encoding a protein, but required for the negative regulation of developmentally important mRNAs (Ambros 2004; Chen 2005). We now know that the transcripts of these noncoding RNA loci are processed into small (micro) RNAs with perfect or near-perfect complementarity to the down-regulated mRNAs. miRNAs with mismatches relative to their target mRNAs tend to repress translation by binding stably to the mRNA, hence interfering with the translation machinery. By contrast, miRNAs with perfect complementarity to their target mRNAs tend to induce mRNA cleavage through slicing by the PIWI domain of the associated AGO protein. In animals, in which miRNAs rarely match their target mRNAs perfectly, translation inhibition is the most prevalent form of miRNA action (Ambros 2004; Bartel 2004). In plants, perfect or near-perfect complementarity of plant miRNAs to their target mRNAs is the norm, thereby favoring mRNA slicing (Jones-Rhoades et al. 2006; Axtell et al. 2011; Cuperus et al. 2011). However, these are tendencies, not rules, such that some plant miRNAs and siRNAs block translation, and some mammalian miRNAs direct mRNA slicing.

miRNAs are transcribed by DNA-dependent RNA Pol II, sometimes as separate miRNA genes and sometimes as sequences present within long noncoding RNAs or in introns of protein-coding genes. As in animals, plant miRNAs originate from 70 - to more than 600 -bp-long precursor RNAs that fold back to form imperfect hairpin or stem-loop structures (Bartel 2004; Jones-Rhoades et al. 2006; Cuperus et al. 2011). In mammals, the RNase III-related endonuclease, Drosha, cleaves the initial pri-miRNA stem-loop precursor on the loop-proximal side of the stem, aided by the dsRNA binding protein, Pasha. Alternatively, in the case of intron-encoded miRNAs, or 
"mirtrons," splicing and lariat debranching enzymes generate the initial pre-miRNA (Okamura et al. 2007; Westholm and Lai 2011). The resulting partially processed preRNA is then transported to the cytoplasm by an Exportin 5 -mediated pathway to undergo further processing. In the cytoplasm, Dicer cuts the stem at a site $22 \mathrm{nt}$ from the Drosha cleavage site, thereby generating a duplex that includes the mature miRNA, or miR, and the complementary passenger strand, miR* (Du and Zamore 2005; Carthew and Sontheimer 2009). Plants, however, lack Drosha and Pasha orthologs and are thought to generate miRNAs entirely within the nucleus, with DCL1 responsible for both cleavages of the stem-loop precursor RNA, generating $\mathrm{miR} / \mathrm{miR}^{*}$ duplexes that are typically 21 -nt long (Fig. 3). DCL1 processing is assisted by the RNA-binding proteins HYPONASTIC LEAVES 1 (HYL1; also known as DRB1) and DAWDLE (DDL), as well as a zinc-finger protein, SERRATE (SE). The $\mathrm{miR} / \mathrm{miR}^{*}$ duplex is then methylated by HUA ENHANCER 1 (HEN1) at the 3 '-terminal ribose of each RNA strand, thereby protecting the small RNAs from uridylation and increasing their stability. Most methylated $\mathrm{miR} / \mathrm{miR}^{*}$ duplexes are then thought to be exported from the nucleus to the cytoplasm in a process involving HASTY (HST), a homolog of mammalian Exportin 5. However, the abundance of specific miRNAs is differentially affected in hst mutants, suggesting variation in the trafficking of different miRNAs. The miR strand is loaded onto AGO1, or a related AGO family member, including AGO10 or AGO7, and the resulting AGO-RISC complex carries out slicing or translational inhibition of mRNAs complementarity to the miRNA (reviewed in Chen 2009; Poethig 2009; Axtell et al. 2011; Cuperus et al. 2011).

Comparative analyses of angiosperms (flowering plants), gymnosperms, and more primitive plants, such as ferns and mosses, have identified a number of highly conserved miRNAs that are critical for meristem function and development (Axtell et al. 2007; Axtell and Bowman 2008). Although the coding sequences of the mRNAs targeted by these miRNAs have changed during evolution, the miRNA-binding sites within the mRNAs are nearly invariant, indicating that the need for such complementarity has constrained the evolution of the matching miRNA and mRNA sequences for at least 400 million years.

AGO1 is the founding member of the AGO protein family and is the principal mRNA slicer in Arabidopsis for DCL1-, DCL2-, and DCL4-generated small RNAs (Baumberger and Baulcombe 2005). AGO1 was identified as an Arabidopsis mutant defective in leaf development before the discovery of miRNAs. The name "Argonaute" was inspired by the phenotype of ago1 mutants, whose narrow, filamentous leaves gave the plants the appearance of a small octopus of the genus Argonauta. Agol hypomorphic mu- tants display severe shoot apical meristem defects, as do ago10 mutants. The latter are also known as pinhead (pnh) mutants (see Table 1) because of the absence of lateral organ formation at the shoot apex. These dramatic apical meristem phenotypes derive from defects in stem cell maintenance and cell lineage specification (reviewed in Kidner and Martienssen 2005; Vaucheret 2008).

Approximately $50 \%$ of the known miRNA targets in Arabidopsis are transcription factors, many of which modulate meristem formation and identity. Other miRNAs target mRNAs encoding F-box proteins that are involved in the ubiquitin-mediated turnover of proteins in developmentally important signaling pathways. The biogenesis of some miRNAs is induced by specific environmental stresses, leading to down-regulation of complementary mRNAs during adaptive stress responses (Axtell and Bowman 2008; Poethig 2009; Cuperus et al. 2011).

An interesting regulatory strategy in plants is the use of decoys to sequester specific miRNAs from key targets. For instance, one function attributed to AGO10 is the sequestration of miR166/165 so as to make the miRNAs unavailable to AGO1 (Zhu et al. 2011a). In other cases, mRNAs with imperfect complementarity to miRNAs serve as decoys, or target mimics, that tie up miRNA-AGO RISC complexes such that other mRNA targets escape inactivation (Franco-Zorrilla et al. 2007). Interestingly, AGO1 and DCL1 are themselves targeted by miRNAs, allowing for negative feedback of miRNA biogenesis.

Mature miRNAs are detected in both the nucleus and cytoplasm, suggesting that miRNAs may have functions in both cellular compartments. Evidence that miRNAs can direct DNA cytosine methylation was among the earliest clues that miRNAs can regulate nuclear activities (Bao et al. 2004). There is also evidence that posttranscriptional silencing can be mediated by small RNA-guided cleavage of intronic sequences (Hoffer et al. 2011). Collectively, these observations suggest that pre-mRNAs have the potential to be targeted by miRNA or siRNA RISCs before mRNA maturation or export to the cytoplasm. Whether dedicated machinery exists for RISC trafficking from the cytoplasm to the nucleus, or whether RISC assembly can occur in both compartments, is not clear.

\subsection{Trans-Acting siRNAs}

Most miRNAs directly regulate specific mRNAs. However, plants have evolved another pathway in which miRNAs initiate the production of secondary siRNAs that then target mRNAs (Fig. 4). This so-called tasiRNA pathway gets its name because the secondary siRNAs act on loci that are distinct from the loci that give rise to the siRNAs (reviewed in Chen 2009; Chuck et al. 2009; Allen and Howell 2010). 


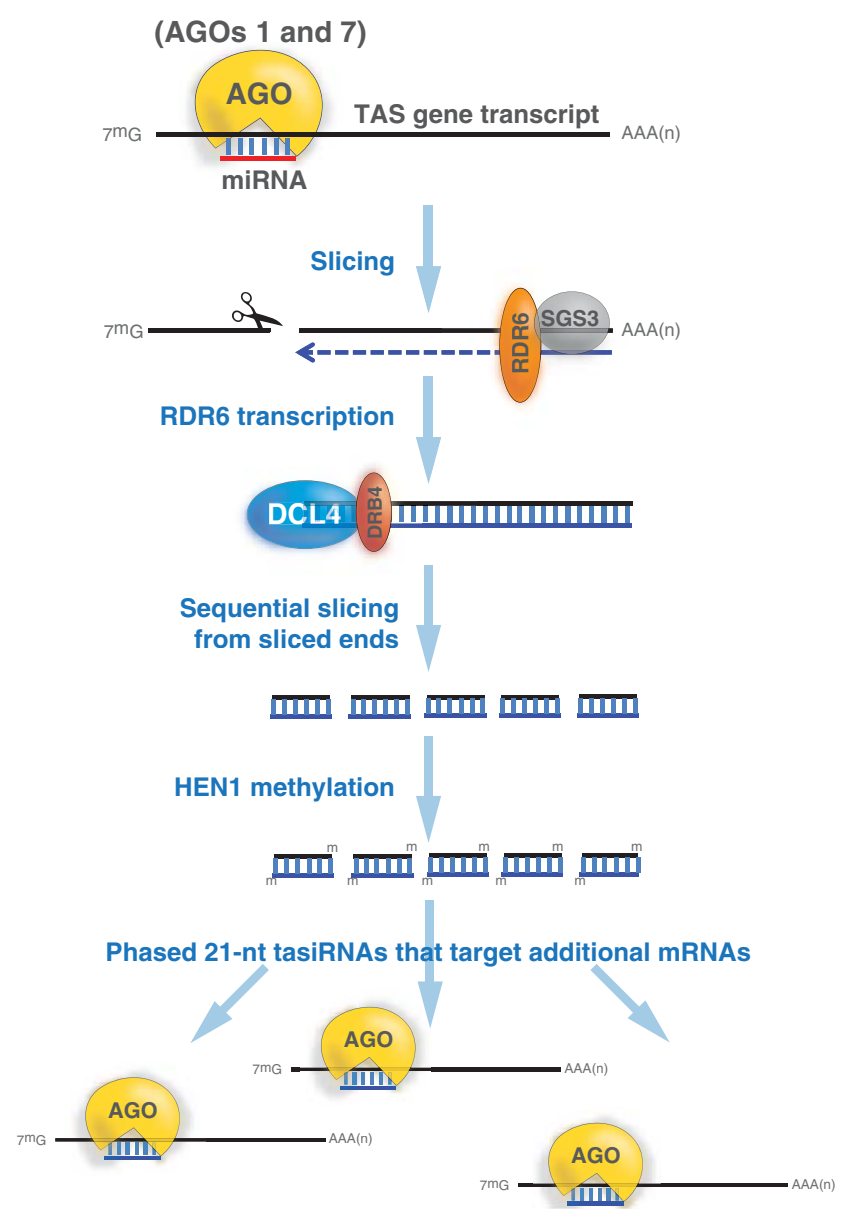

Figure 4. tasiRNA biogenesis and function. Specific miRNAs, associated with AGO1 or AGO7, target and cleave the transcripts of TAS gene loci, ultimately giving rise to tasiRNAs. In the case of AGO1, initiating miRNAs that are $22 \mathrm{nt}$ in length induce the recruitment of the RNA-dependent RNA polymerase, RDR6 (and its partner SGS3), to the $3^{\prime}$ cleaved fragment resulting in transcription of the complementary strand to generate dsRNA. Dicing by DCL4, aided by the dsRNA-binding protein, DRB4, results in the production of 21-nt tasiRNAs that are phased with respect to the miRNA-cleaved end. These tasiRNAs, in turn, target specific complementary RNAs in association with AGO1, thus behaving like target-specific miRNAs.

In Arabidopsis, there are four families of TAS gene, loci that generate tasiRNAs: TAS $1-4$. TAS1 and TAS2 are both targeted by miR173 in association with AGO1, TAS4 is targeted by miR828-AGO1, and TAS3 is targeted by miR390AGO7 (Montgomery et al. 2008). TAS loci generate long noncoding RNAs that are cleaved by the miRNA-AGORISC complex, triggering the conversion of the $3^{\prime}$ cleavage product into dsRNA through the action of RNA-DEPENDENT RNA POLYMERASE 6 (RDR6) and its partner, SUPPRESSOR OF GENE SILENCING 3 (SGS3). The dsRNA is then diced by DCL4 into 21-nt tasiRNAs that are phased with respect to the original miRNA cleavage site, such that tasiRNA sequences have defined sequences, much like miRNAs, and function like miRNAs to direct the slicing of downstream complementary target mRNAs (Fig. 4). The tasiRNAs produced by the TAS3 locus target several Auxin response factor mRNAs, thereby affecting developmental transitions that are regulated by the plant hormone auxin. By modification of auxin responses, tasiRNAs contribute to the transition of the meristem from a juvenile phase, with vegetative organs only, to an adult phase capable of responding to signals promoting flowering (Poethig et al. 2006).

\section{4 siRNA-Mediated Silencing as a Genome Defense Strategy}

Multifunctional siRNA-AGO complexes and/or dicer endonucleases have evolved as useful components in the defense against viral and microbial pathogen attack (Martienssen and Moazed 2014). Most plant viruses are RNA viruses whose dsRNA forms are subject to DCL-catalyzed dicing and degradation. For DNA viruses, such as geminiviruses or Cauliflower Mosaic Virus, the viral genome can be the target of siRNA-mediated DNA methylation, or siRNAs can facilitate the degradation or inactivation of viral transcripts, resulting in transcriptional silencing and decreased viral RNA synthesis. Defense against foreign or invasive nucleic acids thus provides the most likely explanation for the evolution of small RNA-mediated RNAi pathways in eukaryotes and for the diversification of RNA-silencing capabilities in plants (Ding 2010). These include the ability to silence genes at a transcriptional and/or posttranscriptional level and an ability to spread defensive small RNAs to cells distant from the site of initial infection, thereby arming the plant against a spreading virus, enabling it to mount a systemic defense (illustrated in Fig. 1 of Dunoyer et al. 2013).

Most plant viruses are single-stranded RNA viruses whose replication by endogenous or viral encoded RNAdependent RNA polymerase transcription produces dsRNA intermediates (Wassenegger and Krczal 2006) that can be diced into $21-24$-nt siRNAs, primarily by DCLs $2,-3$, and -4 (Fig. 5) (Vazquez et al. 2010). Other plant viruses have dsRNA genomes providing direct substrates for Dicer cleavage. Single-stranded DNA viruses, such as geminiviruses, replicate via double-stranded DNA intermediates and generate RNA transcripts from both strands of the DNA. These RNAs can overlap and base-pair resulting in dsRNA that can be diced. Alternatively, long viral RNA transcripts might fold back on themselves into structures with some dsRNA regions that might be diced. Thus, antiviral RNAi responses can be enabled by dsRNAs produced by the virus itself. 

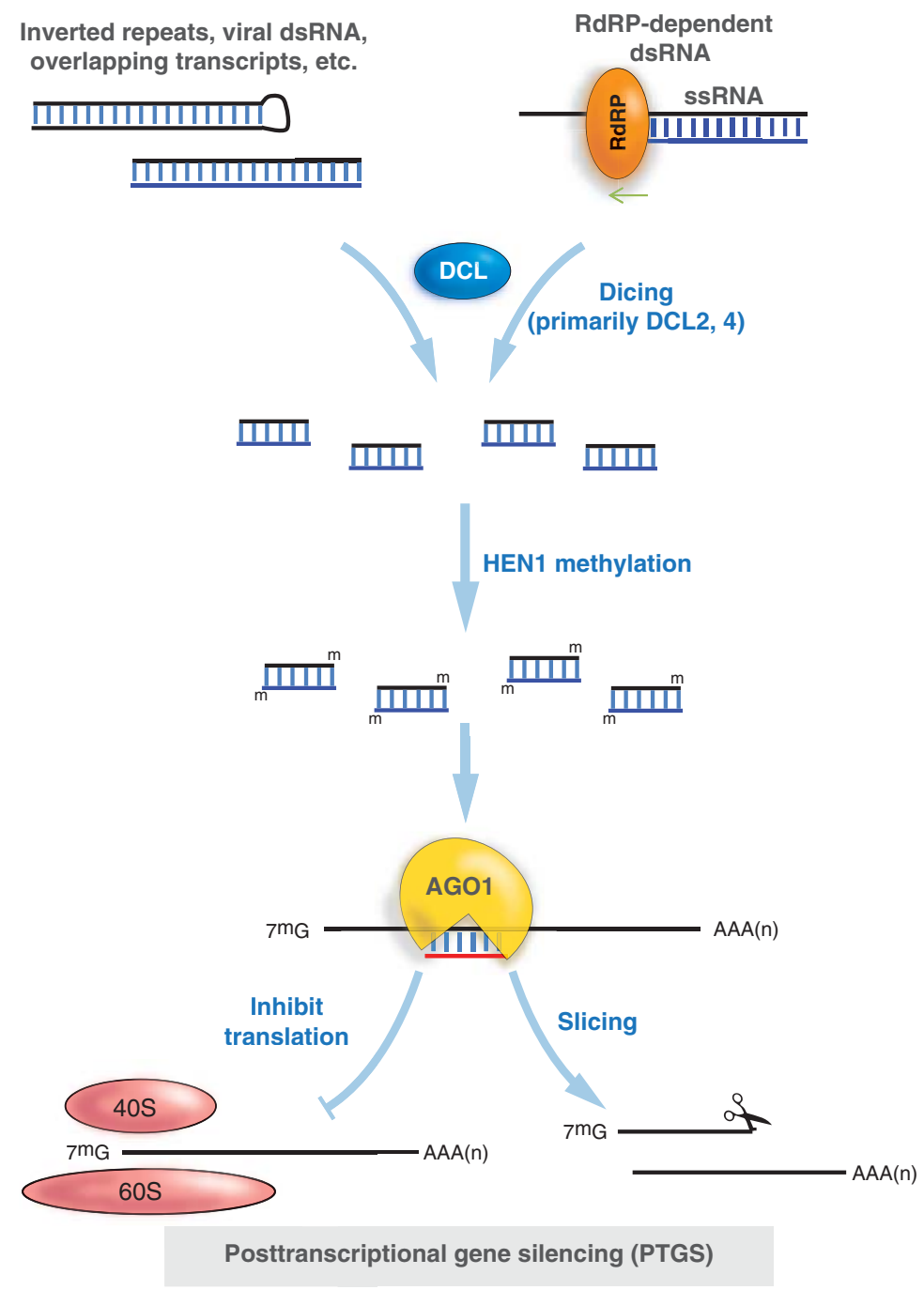

Figure 5. PTGS induced by viruses or transgenes. Double-stranded precursors of siRNAs that bring about PTGS can be dsRNA viral genomes or replication intermediates, dsRNAs formed by overlapping transcripts from adjacent transcription units, or inverted repeats resulting from tandem transgenes that integrate in opposite orientations. Alternatively, single-stranded RNAs can be made double-stranded by the action of RNA-dependent RNA polymerases, such as RDR6 or RDR1. Dicing can then occur by DCLs 2, -3 or -4, with 22-nt DCL2 products and 21-nt DCL4 products being primarily associated with PTGS. On association with AGO1, the siRNAs target complementary RNAs for degradation or translational inhibition.

Transgenes introduced into plant genomes can fall victim to silencing pathways that probably evolved for antiviral defense, as illustrated in Figure 5. This occurs because transgenes often integrate in multiple copies, and in inverted orientation relative to one another. Thus, readthrough transcripts that extend from one transgene into an adjacent transgene integrated in the opposite orientation produce RNA with regions of self-complementarity, or inverted repeats, resulting in dsRNA that can be diced. A transgene might also integrate into a chromosome adjacent to a strong promoter pointed in the opposite orientation relative to the transgene's promoter, resulting in convergent bidirectional transcription and dsRNA formation.

PTGS of transgenes and VIGS involve the production of 21-24-nt siRNAs generated by DCLs 2, -3 , and -4 (Fig. 5). In general, the 21- and 22-nt siRNAs generated by DCL4 are thought to guide mRNA cleavage in association with AGO1. Following endonucleolytic cleavage by a $21-\mathrm{nt}$ siRNA-AGO1 complex, the severed $3^{\prime}$ segment of the mRNA lacking a 7-methylguanosine cap at the $5^{\prime}$ end is degraded in the $5^{\prime}$ to $3^{\prime}$ direction by the exonuclease, AtXRN4 (Rymarquis et al. 2011). The $5^{\prime}$ fragment is probably degraded by the exosome in a $3^{\prime}$ to $5^{\prime}$ direction. An 
intriguing property of 22-nt small RNAs, which are less abundant than 21-nt siRNAs, is that their association with AGO1 brings about mRNA cleavage that is coupled to the recruitment of RDR6, similar to the action of the 22nt miRNAs that give rise to tasiRNAs. As a result, the $3^{\prime}$ AGO cleavage fragment is converted into a dsRNA, which is then diced by DCL4 to generate 21-nt secondary siRNAs (Chen et al. 2010; Cuperus et al. 2010; Manavella et al. 2012).

siRNAs that are generated by DCL3 associate primarily with AGO4, or the related AGO6 or AGO9 proteins ( $\mathrm{Ha}-$ vecker et al. 2010), and can direct RNA slicing of viral or transgene-derived RNAs. However, these 24-nt siRNAAGO RISC complexes have the added property of directing epigenetic modifications to homologous DNA sequences (see Sec. 3.5.1). The combination of mRNA degradation, production of secondary siRNAs, and transcriptional silencing constitutes a potent response to an invading nucleic acid. However, it is not surprising that viruses have evolved counter-measures, encoding proteins that suppress RNA silencing (discussed in Baulcombe and Dean 2014), in an evolutionary arms race between pathogen and host (reviewed in Ding and Voinnet 2007; Bivalkar-Mehla et al. 2011).

\subsection{RNA-Directed DNA Methylation and Heterochromatin Formation}

RNA-mediated transcriptional silencing of transposons, retroviruses, and other genomic repeats is well documented in diverse eukaryotes, including plants, mammals, fission yeast, and fruit flies. In fission yeast and fruit flies, which do not use DNA methylation as part of their gene silencing toolkit, small RNAs mediate changes in histone modification to bring about transcriptional silencing (detailed in Elgin and Reuter 2013 and Allshire and Ekwall 2014). However, in plants and mammals, which methylate their DNA, cytosine methylation and repressive histone modifications are partners in the silencing of repetitive elements and the specification of heterochromatin. In plants, the silencing of facultative heterochromatin, which includes retrotransposons and other expressed repeats such as excess rRNA genes, involves 24-nt siRNAs that direct the de novo cytosine methylation of corresponding genomic sequences (Matzke et al. 2009; Law and Jacobsen 2010; Haag and Pikaard 2011; Zhang and Zhu 2011). In the male germline of mammals, small RNAs similarly associate with proteins of the PIWI subfamily of AGO proteins (piRNAs) and are implicated in directing histone modifications and de novo cytosine methylation of transposons (Klattenhoff and Theurkauf 2008; He et al. 2011; Pillai and Chuma 2012).

\subsubsection{RdDM}

RdDM was first observed in tobacco plants infected with viroids (Wassenegger et al. 1994). Viroids are plant pathogens consisting solely of a circular noncoding RNA only several hundred nucleotides in length. Replicating viroids were found to trigger de novo methylation of viroid cDNAs that had been integrated as transgenes into the tobacco genome. RNA viruses were similarly found to elicit the methylation of homologous DNA sequences in the nuclear genome. Moreover, by expressing transgenes engineered to express dsRNAs homologous to promoter sequences, cytosine methylation was shown to be directed to the promoter, resulting in homology-dependent transcriptional silencing of the corresponding gene (Mette et al. 2000).

RdDM is typified by the methylation of cytosines primarily within the region of RNA-DNA sequence identity, although RNA-mediated spreading to other sequences can occur (see Sec. 3.6). RdDM establishes methylation in all sequence contexts (see Sec. 2.1), but CHH methylation is a specific hallmark of RdDM. This is because symmetrical CG and CHG methylation can be perpetuated at every round of replication by maintenance methylation, but perpetuation of $\mathrm{CHH}$ methylation at many silenced loci requires continuous, RNA-guided de novo methylation in every cell cycle (Law and Jacobsen 2010).

Combined data from forward and reverse genetic screens have revealed many of the key molecular components needed for RNA-directed DNA methylation and TGS (see Secs. 2.1 and 2.2). These genetic screens have relied on reporter transgenes or endogenous genes having a visible phenotype when silenced, allowing mutants that release (or prevent) silencing to be readily identified.

\subsubsection{Plant-Specific Machinery for RNA-Directed DNA Methylation}

As explained previously (Sec. 2.1.1), de novo methylation during RdDM is catalyzed by the DRM class of DNA methyltransferases. The full details of how DRM2 is recruited to DNA are not yet clear. However, a number of key activities have been identified, revealing a critical role for noncoding RNAs and siRNAs to allow the DNA methylation machinery to hone in on its target sites (Fig. 6).

All known eukaryotes have three highly conserved nuclear multisubunit DNA-dependent RNA polymerases that are essential for viability: RNA Pol I, II, and III. Interestingly, plants have evolved two additional nuclear DNAdependent RNA polymerases-RNA Pol IV (in the early literature referred to as RNA Pol IVa) and RNA Pol V (previously referred to as RNA Pol IVb) - that play important roles in RdDM in Arabidopsis (Haag and Pikaard 2011). It is clear that RNA Pols IV and Vevolved as specialized forms 


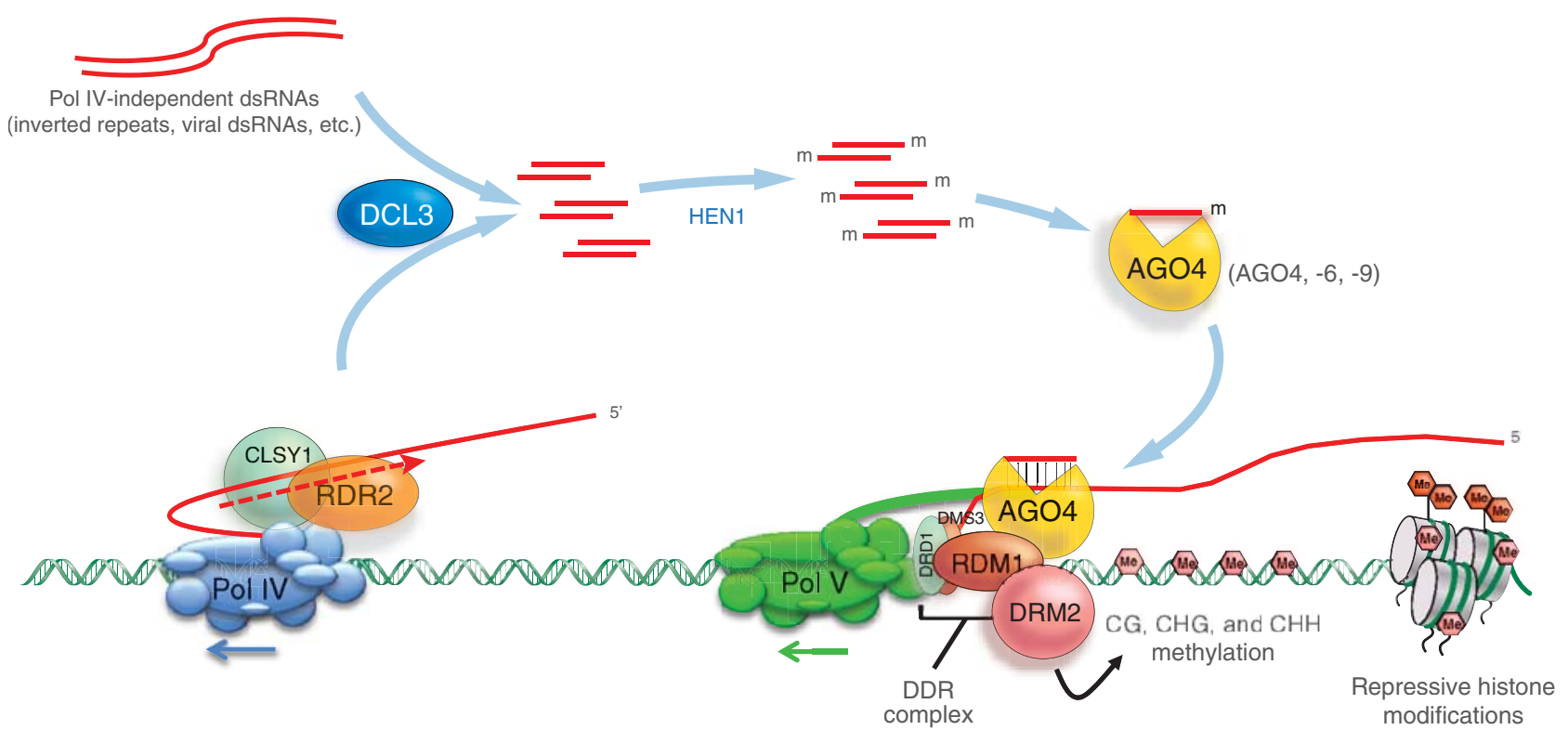

\begin{abstract}
Figure 6. RdDM. Retrotransposons, viruses, transgenes, or repetitive genes are subject to silencing by RdDM. RNA Pol IV is thought to generate single-stranded RNAs (bottom left) that serve as templates for the RNA-dependent RNA polymerase, RDR2. Resulting dsRNAs are diced by DCL3 to generate 24-nt siRNA duplexes that are then methylated by HEN1 and loaded onto AGO4, or its closely related family members, AGO6 or AGO9. dsRNA derived from inverted repeat transgenes or viruses (top left) can bypass the need for RNA Pol IV and RDR2. AGO-siRNA complexes are recruited to their sites of action by binding to transcripts generated by RNA Pol V, as well as by physical interactions with the carboxy-terminal domain of the RNA Pol V largest subunit. At some loci, RNA Pol II is thought to substitute for RNA Pol V for the production of scaffold transcripts to which AGO-siRNA complexes bind. The DDR complex (DRD1, DMS3, and RDM1) enables RNA Pol V transcription. The RDM1 subunit of the DDR complex also interacts with AGO4 and the de novo cytosine methyltransferase, DRM2, thus potentially serving as a bridge that recruits DRM2 to sites of RNA Pol V transcription.
\end{abstract}

of RNA Pol II, a process that began in green algae before the emergence of land plants (Luo and Hall 2007; Tucker et al. 2010). Arabidopsis RNA Pols II, IV, and Veach have 12 core subunits, approximately half of which are common to all three polymerases and encoded by the same genes (Ream et al. 2009). Subunits that are unique to RNA Pols IV or V are encoded by genes that arose via the duplication of RNA Pol II subunit genes, followed by subfunctionalization. For some subunits, there are two or more variants (Ream et al. 2009; Law et al. 2011). These alternative subunits can confer different capabilities to the enzymes, suggesting that there are multiple functional subtypes of RNA Pols II, IV, and V (Tan et al. 2012).

RNA Pol IV and Pol V have distinct roles in the RdDM pathway (reviewed in Matzke et al. 2009; Lahmy et al. 2010; Law and Jacobsen 2010; Haag and Pikaard 2011; Zhang and Zhu 2011). RNA Pol IV is thought to act early in the pathway because it colocalizes with genetic loci that give rise to abundant 24-nt siRNAs and is required for their biogenesis. Moreover, the loss of RNA Pol IV activity causes other proteins of the RdDM pathway to mislocalize. Genetic and biochemical evidence suggest that RNA Pol IV transcripts serve as templates for RNA-DEPENDENT RNA POLYMERASE 2 (RDR2), thereby generating dsRNAs. RNA Pol IV and RDR2 physically interact in vivo, with evidence that their activities are mechanistically coupled, allowing for the channeling of precursor RNAs for 24-nt siRNA biogenesis (Haag et al. 2012). CLSY1, a putative ATP-dependent chromatin remodeler in the SWI2/SNF2 helicase domain protein family, is thought to assist the RNA Pol IV-RDR2 transcription complex. As a result, nuclear localization patterns of RNA Pol IV and RDR2 are perturbed in $c l s y 1$ mutants.

dsRNAs that result from the collaboration of RNA Pol IV with RDR2 are cleaved into 24-nt duplexes by DICERLIKE 3 (DCL3), and HEN1 methylates the three ends of the siRNAs on their $2^{\prime}$ hydroxyl groups, helping to stabilize the siRNAs in the same way as for miRNAs (see Sec. 3.2). One strand of the duplex is then loaded into AGO4, or the closely related 24-nt siRNA-binding proteins, AGO6 or AGO9. Recruiting the resulting siRNA-AGO complexes is the function of RNA Pol V, whose RNA transcripts have been detected at a number of loci that are subjected to RdDM. These RNAs are dependent on the RNA Pol Vactive 
site and can be chemically crosslinked to RNA Pol V, suggesting that they are direct RNA Pol V transcripts. RNA Pol $\mathrm{V}$ transcription does not require siRNA biogenesis, but is dependent on the putative chromatin remodeler, DRD1, DMS3 (a protein that shares homology with the hinge domain regions of structural maintenance of chromosomes proteins, such as cohesins and condensins; Wierzbicki et al. 2008; Wierzbicki et al. 2009) and REQUIRED FOR DNA METHYLATION1 (RDM1), a single-stranded DNA-binding protein with a preference for binding methylated DNA in vitro. DRD1, DMS3, and RDM1 physically associate within a multifunctional complex (DDR) that copurifies with RNA Pol V (Law and Jacobsen 2010; Zhang and Zhu 2011). Whether the DDR complex recruits RNA Pol V to target loci or mediates RNA Pol V transcriptional elongation is still unclear.

Based on chemical crosslinking and immunoprecipitation studies, current models suggest that AGO4-RISC complexes are recruited to target loci by siRNA basepairing to RNA Pol V transcripts (Wierzbicki et al. 2008; Wierzbicki et al. 2009). In this way, RNA Pol V transcripts are thought to serve as scaffolds for recruiting the chromatin-modifying machinery into proximity of the chromatin to be modified. AGO4 also binds tryptophan (W) and glycine (G) WG and GW repeats within the carboxyterminal domain of the Pol V largest subunit, further contributing to RISC assembly at Pol V-transcribed loci (Lahmy et al. 2010).

Two AGO4-interacting proteins are important for RdDM: INVOLVED IN DE NOVO 2 (IDN2/RDM12), a protein that binds dsRNAs with $5^{\prime}$ overhangs, possibly siRNAs base-paired with RNA Pol V transcripts, and KOW DOMAIN-CONTAINING TRANSCRIPTION FACTOR (KTF1, also known as RDM3 or SPT5-LIKE) that shares similarity with the yeast RNA Pol II transcription factor, SPT5 (Lahmy et al. 2010; Law and Jacobsen 2010; Zhang and Zhu 2011). In vitro, KTF1 binds RNA and has a WG/GW-rich domain that facilitates interactions with AGO4. KTF1 might therefore play a role in the recruitment of AGO4 to RNA Pol V transcripts, promoting AGO4 slicing of RNA Pol V transcripts as well as recruitment of downstream silencing components.

At present, it is not clear how DRM2 DNA methyltransferase is recruited to Pol V-transcribed loci, but the RDM1 protein of the DDR complex might serve as a bridge between AGO4 and DRM2 (Zhang and Zhu 2011). RDM1 also interacts with RNA Pol II, which can substitute for RNA Pol $\mathrm{V}$ in the production of scaffold transcripts at some loci and is also implicated in the recruitment of RNA Pol IV and Pol Vat some loci (Zheng et al. 2009). RDM1 might therefore be a key protein that can mediate DRM2 recruitment in both RNA Pol V- and Pol II-dependent pathways.
A classic epigenetic phenomena, first discovered in maize, is paramutation, the heritable alteration of gene activity that can occur when certain active and silenced alleles are brought together within the same nucleus. Maize genes required for paramutation include MAINTENANCE OF PARAMUTATION 1 (MOP1; the ortholog of Arabidopsis RDR2); REQUIRED TO MAINTAIN REPRESSION 6 (RMR6; the ortholog of the Arabidopsis RNA Pol IV largest subunit, NRPD1); RMR1, a putative chromatin remodeling ATPase related to CLSY1 and DRD1; and MOP2/ RMR7, one of three homologs of the second-largest subunit of Arabidopsis RNA Pol IV and Pol V (Arteaga-Vazquez and Chandler 2010; Erhard and Hollick 2011). These findings clearly implicate proteins of the RdDM pathway in paramutation yet it remains unclear whether RNA-directed cytosine methylation occurs at paramutable and paramutagenic loci.

\subsubsection{Repressive Histone Modifications Associated with Transcriptional Gene Silencing}

At loci subjected to RdDM, the methylated DNA is wrapped by histones that bear posttranslational modifications typical of heterochromatin. Such a condensed chromatin state is refractive to transcription by RNA Pol I, II, or III, but enables transcription by Pol IV and Pol V. Several chromatin-modifying enzymes involved in establishing or maintaining heterochromatin (see Sec. 2.2) have been identified in genetic screens for mutants that interfere with RdDM. These include histone H3K9 and H3K27 methyltransferases, the broad-specificity histone deacetylase HDA6, UBIQUITIN PROTEASE 26 (UBP26 or SUP32), which is required to deubiquitinate histone $\mathrm{H} 2 \mathrm{~B}$, and JMJ14, a JumonjiC domain-containing protein that demethylates H3K4me3, a modification typical of actively transcribed loci. Collectively, these activities are indicative of a silencing process that includes the establishment of chromatin marks typical of the silenced state (reviewed in Matzke et al. 2009; Lahmy et al. 2010; Law and Jacobsen 2010; Haag and Pikaard 2011; Zhang and Zhu 2011).

\subsubsection{RNA-Mediated Silencing of Endogenous Genes}

Most RNA-directed DNA methylation and TGS is focused on retrotransposons and repetitive genetic elements that are remnants of transposons, presumably as a means of transposon taming to keep their proliferation in check (Zaratiegui et al. 2007). One consequence is that a number of regulatory genes are affected by their proximity to transposons or repetitive elements. For example, transposonderived repeats in the promoter of the Arabidopsis 
flowering time gene FWA are targeted by RdDM, thus silencing the gene. Because many plant genes have transposon insertions in the vicinity of promoters or in introns, this mode of regulation is likely to be common in the plant kingdom. Indeed, Barbara McClintock's hypothesis that transposons act as controlling elements regulating adjacent host genes (McClintock 1950) has been confirmed in multiple cases.

Not all repetitive sequences subjected to RdDM share a connection with transposons or are likely candidates for being targeted by machinery adapted for genome defense. Notable examples are the repetitive 5S rRNA genes transcribed by RNA Pol III and the 45S ribosomal RNA genes transcribed by RNA Pol I (Layat et al. 2012). These genes are essential for ribosome synthesis and are clustered in long tandem arrays at several loci, each having hundreds of gene copies. RdDM appears to help shut down excess rRNA genes such that their effective dosage can be regulated according to the cellular demand for ribosomes and protein synthesis (Preuss et al. 2008).

\subsection{Amplification and Spreading of siRNA-Mediated Silencing}

An important aspect of siRNA-mediated silencing in plants is that initial siRNA production can trigger additional, secondary siRNAs. Moreover, siRNAs can move from cell to cell or be transported to other organs, thereby amplifying siRNA-mediated silencing ultimately executed at the transcriptional or posttranscriptional levels (see also Dunoyer et al. 2013; Baulcombe and Dean 2014).

\subsubsection{Transitivity}

Transitivity is a term used to describe the generation of secondary siRNAs that are induced by a primary siRNA trigger. For instance, two adjacent genes that point toward one another can generate transcripts that overlap in their $3^{\prime}$ regions and can base-pair. Dicing of the resulting dsRNA in the region of overlap can generate primary siRNAs that can then base-pair with a complementary long mRNA (or other long RNA) sequence and prime transcription by RNAdependent RNA polymerase, particularly RDR6. The result is a dsRNA that extends from the siRNA primer to the $5^{\prime}$ end of the RNA template. Subsequent dicing of these dsRNAs generates secondary RNAs corresponding to upstream $\left(5^{\prime}\right)$ regions (left side of Fig. 7).

Secondary siRNAs can also be generated in the region $3^{\prime}$ of a primary siRNA (or miRNA) trigger, as described for trans-acting siRNAs whose biogenesis is triggered by an miRNA. In this case, siRNA or miRNA-mediated cleavage of an RNA transcript facilitates the use of the uncapped $3^{\prime}$ fragment as a template for primer-independent RDR6 transcription (right side of Fig. 7). The mechanistic details of how this occurs are not yet clear, but RDR6 must initiate transcription from the $3^{\prime}$ end of the RNA fragment, a site that is distal from the siRNA or miRNA cleavage site. This process is specifically triggered by 22-nt siRNAs or 22-nt miRNAs that associate with AGO1 (Chen et al. 2010; Cuperus et al. 2010; Manavella et al. 2012), but not by 21-nt siRNA-AGO1 complexes. Although 22-nt miRNAs are not common, they can be produced by DCL1 from dsRNA hairpin precursors that have an extra nucleotide in the miR strand relative to the 21-nt $\mathrm{miR}^{*}$ strand, forming a bulge that does not inhibit dicing. Presumably, a change in AGO1 conformation, or its association with other required proteins, occurs on binding 22-nt siRNAs, and results in the recruitment of RDR6. The resulting dsRNA is then diced by DCL4, with the help of the dsRNA binding protein DRB4, generating 21-nt secondary siRNAs that correspond to the region downstream from the primary siRNA or miRNA trigger.

Overall, the ability to produce secondary siRNAs both upstream of and downstream from the region complementary to the primary siRNA(s) magnifies the RNA silencing response, thus strengthening the plant's resistance to an invading virus or nucleic acid (Brodersen and Voinnet 2006).

\subsubsection{Non-Cell-Autonomous Silencing}

Small RNAs can bring about posttranscriptional or transcriptional silencing in neighboring cells or even in cells in distant organs. For short-range movement, RNAs travel from their cell of origin into neighboring cells through plasmodesmata. This conclusion is supported by the fact that guard cells, which form the openings (stomata) for gas exchange in leaves, lack plasmodesmata and are excluded from receiving silencing signals from adjacent cells (Voinnet et al. 1998). Long-range movement is a consequence of RNA loading into phloem cells, allowing their transport through the vascular system followed by their unloading and cell-to-cell spread in recipient tissues. This was shown in grafting experiments involving transgenes, mutants, and deep sequencing of small RNAs (Dunoyer et al. 2013).

Evidence that mobile RNAs are important transmitters of information between plant cells extends to the male and female gametophytes. In pollen, there is evidence that small RNAs produced by the vegetative cell can direct silencing in the two sperm cells. The hypothesis is that derepression of transposable elements in the vegetative cell allows for the biogenesis of siRNAs that then move to the sperm cells to reinforce the silencing of the corresponding transposons. In this way, epigenetic programming in sperm cells, in 


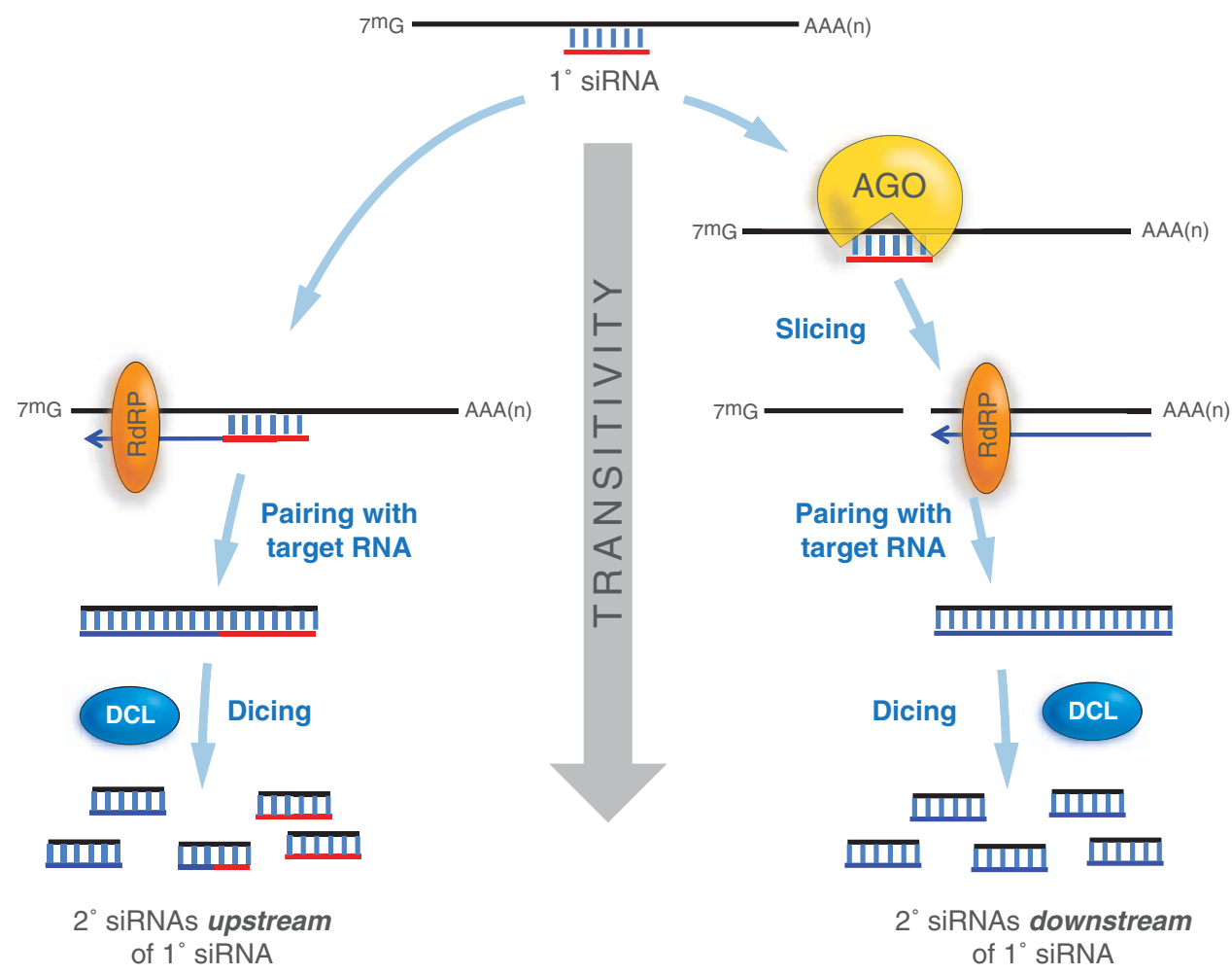

Figure 7. Transitivity: amplification and spreading of secondary siRNAs from the site of a primary siRNA target. Primary siRNAs are thought to prime RNA-dependent RNA polymerase activity, resulting in dsRNAs extending toward the $5^{\prime}$ end of the target RNA (left). Subsequent dicing gives rise to secondary siRNAs in the region upstream of the initiating primary siRNA. 22-nt siRNAs also have the property of recruiting RDR6 to the 3' fragment following AGO slicing (right), resulting in dsRNA and secondary siRNA biogenesis in the region downstream from the initiating, primary siRNA.

which transposition would result in frequent deleterious mutations, is guaranteed via the activity of the vegetative cell, which does not contribute genomic information to the next generation through fertilization (Slotkin et al. 2009). Likewise, abundant RNA Pol IV-dependent siRNAs of maternal origin accumulate in embryos and developing seeds and may play roles in the epigenetic reprogramming of paternal chromosomes (Mosher et al. 2009).

\section{OUTLOOK}

The past decade has witnessed an explosion of information concerning the proteins, RNAs, and chemical modifications that contribute to epigenetic control. However, there is much to learn about the nature of epigenetic inheritance and the role of epigenetics as a source of variation contributing to fitness and natural selection. Much of what we know thus far has come from the analysis of mutants generated using harsh mutagenesis treatments and comparison of these mutants, under laboratory conditions, to nonmutagenized reference plants referred to as being "wild type." Breeders have long known that wildtype plants collected from different geographical origins are themselves a rich source of genetic diversity. Natural variation among ecotypes-strains or races of a species that are adapted to specific niches-reflects naturally occurring nucleotide sequence changes, recombination, or transposition events, gains, or losses of DNA sequences, or hybridization events. In plants with a high degree of inbreeding such as $A$. thaliana, individual ecotypes display a high degree of genetic homogeneity. However, the genetic diversity within the species, revealed by genomic comparisons of available ecotypes, is remarkable (http:// 1001genomes.org; Ossowski et al. 2010). It can be expected that the degree of epigenetic variation between ecotypes is also substantial, allowing an opportunity to explore whether epigenetic adaptations contribute to plant form, survival, and performance under different conditions (Becker et al. 2011; Richards 2011; Schmitz et al. 2011). Important agricultural challenges and questions, such as understanding the molecular basis for genotype by environment interactions or heterosis (hybrid vigor), are 
likely to have answers rooted in epigenetic regulatory mechanisms.

Understanding what is genetic and what is epigenetic is not a simple matter. For instance, there is clear evidence for genetic changes that induce switches in epigenetic states (Durand et al. 2012), such as mutations that allow readthrough transcripts to bring about the silencing of adjacent genes, including tumor-suppressor genes in humans. Conversely, epigenetically controlled accessibility of DNA is likely to influence the probability of genetic rearrangements caused by recombination or transposon mobilization (reviewed in Magori and Citovsky 2011; Mirouze and Paszkowski 2011). Understanding the degree to which genetically programmed expression of DNA-binding transcription factors combines with epigenetic mechanisms that limit enhancer or promoter specificity, RNA polymerase processivity, or splice-site selection, is a major challenge for the future.

Our understanding of how environmental conditions such as photoperiod or temperature provoke changes in RNA- or chromatin-based transcriptional regulation is still in its infancy. The majority of these changes lasts only as long as the trigger is present and are therefore not thought to be epigenetic. However, some environmental conditions induce altered chromatin and gene expression states that persist even after a return to the original environmental condition, as in the case of vernalization (Baulcombe and Dean 2014) in which plants "remember" their experience of winter to flower the following spring. There is also the possibility that environmentally or pathogeninduced epigenetic states might be transmitted to progeny if the changes occur in meristems and can be maintained through meiosis. So far, there is only rudimentary evidence for transmission and inheritance of adaptive epigenetic states, as opposed to DNA sequence-based inheritance (Paszkowski and Grossniklaus 2011; Pecinka and Mittelsten Scheid 2012). Nevertheless, with our growing insight into epigenetic regulation and the transmission of mobile small RNAs influencing chromatin states, such neo-Lamarckian possibilities warrant careful consideration.

\section{ACKNOWLEDGMENTS}

We thank Marjori Matzke for her contribution to the first edition. O.M.S. acknowledges funding by the Austrian Academy of Sciences and the Austrian Science Fund (FWF). Pikaard lab research is supported by National Institutes of Health grants GM077590 and GM60380 and C.S.P.'s support as an Investigator of the Howard Hughes Medical Institute and the Gordon \& Betty Moore Foundation.

\section{REFERENCES}

* Reference is also in this collection.

Agius F, Kapoor A, Zhu J-K. 2006. Role of the Arabidopsis DNA glycosylase/lyase ROS1 in active DNA demethylation. Proc Natl Acad Sci 103: 11796-11801.

Alleman M, Doctor J. 2000. Genomic imprinting in plants: Observations and evolutionary implications. Plant Mol Biol 43: 147-161.

Allen E, Howell MD. 2010. miRNAs in the biogenesis of trans-acting siRNAs in higher plants. Semin Cell Dev Biol 21: 798-804.

* Allshire RC, Ekwall K. 2014. Epigenetic regulation of chromatin states in Saccharomyces pombe. Cold Spring Harb Perspect Biol doi: 10.1101/ cshperspect.a018770.

* Almouzni G, Cedar H. 2014. Maintenance of epigenetic information. Cold Spring Harb Perspect Biol doi: 10.1101/cshperspect.a019372.

Ambros V. 2004. The functions of animal microRNAs. Nature 431: $350-$ 355.

Arteaga-Vazquez MA, Chandler VL. 2010. Paramutation in maize: RNA mediated trans-generational gene silencing. Curr Opin Genet Dev 20: $156-163$.

Aufsatz W, Stoiber T, Rakic B, Naumann K. 2007. Arabidopsis histone deacetylase 6: A green link to RNA silencing. Oncogene 26: 5477-5488.

Axtell MJ, Bowman JL. 2008. Evolution of plant microRNAs and their targets. Trends Plant Sci 13: 343-349.

Axtell MJ, Snyder JA, Bartel DP. 2007. Common functions for diverse small RNAs of land plants. Plant Cell 19: 1750-1769.

Axtell MJ, Westholm JO, Lai EC. 2011. Vive la difference: Biogenesis and evolution of microRNAs in plants and animals. Genome Biol 12: 221.

Bao N, Lye KW, Barton MK. 2004. MicroRNA binding sites in Arabidopsis class III HD-ZIP mRNAs are required for methylation of the template chromosome. Dev Cell 7: 653-662.

Bartel DP. 2004. MicroRNAs: Genomics, biogenesis, mechanism, and function. Cell 116: 281-297.

Bartel DP. 2009. MicroRNAs: Target recognition and regulatory functions. Cell 136: 215-233.

Baubec T, Dinh HQ, Pecinka A, Rakic B, Rozhon W, Wohlrab B, von Haeseler A, Mittelsten Scheid O. 2010. Cooperation of multiple chromatin modifications can generate unanticipated stability of epigenetic states in Arabidopsis. Plant Cell 22: 34-47.

Baulcombe DC. 2006. Short silencing RNA: The dark matter of genetics? Cold Spring Harb Symp Quant Biol 71: 13-20.

* Baulcombe DC, Dean C. 2014. Epigenetic regulation in plant responses to the environment. Cold Spring Harb Perspect Biol 6: a019471.

Baumberger N, Baulcombe DC. 2005. Arabidopsis ARGONAUTE1 is an RNA Slicer that selectively recruits microRNAs and short interfering RNAs. Proc Natl Acad Sci 102: 11928-11933.

* Becker PB, Workman JL. 2013. Nucleosome remodeling and epigenetics. Cold Spring Harb Perspect Biol 5: 017905.

Becker C, Hagmann J, Mueller J, Koenig D, Stegle O, Borgwardt K, Weigel D. 2011. Spontaneous epigenetic variation in the Arabidopsis thaliana methylome. Nature 480: 245-249.

Berr A, Shafiq S, Shen W-H. 2011. Histone modifications in transcriptional activation during plant development. Biochim Biophys Acta 1809: $567-576$

Bivalkar-Mehla S, Vakharia J, Mehla R, Abreha M, Kanwar JR, Tikoo A, Chauhan A. 2011. Viral RNA silencing suppressors (RSS): Novel strategy of viruses to ablate the host RNA interference (RNAi) defense system. Virus Res 155: 1-9.

* Blewitt M, Whitelaw E. 2013. The use of mouse models to study epigenetics. Cold Spring Harb Perspect Biol 5: 017939.

Brodersen P, Voinnet O. 2006. The diversity of RNA silencing pathways in plants. Trends Genet 22: 268-280.

Brzeski J, Jerzmanowski A. 2003. Deficient in DNA methylation 1 (DDM1) defines a novel family of chromatin-remodeling factors. J Biol Chem 278: 823-828. 


\section{C.S. Pikaard and O. Mittelsten Scheid}

Butenko Y, Ohad N. 2011. Polycomb-group mediated epigenetic mechanisms through plant evolution. Biochim Biophys Acta 1809: 395-406.

Bycroft M. 2011. Recognition of non-methyl histone marks. Curr Opin Struct Biol 21: 761-766.

Carrington JC, Ambros V. 2003. Role of microRNAs in plant and animal development. Science 301: 336-338.

Carthew RW, Sontheimer EJ. 2009. Origins and mechanisms of miRNAs and siRNAs. Cell 136: 642-655.

Chandler VL, Eggleston WB, Dorweiler JE. 2000. Paramutation in maize. Plant Mol Biol 43: 121-145.

Chapman EJ, Carrington JC. 2007. Specialization and evolution of endogenous small RNA pathways. Nat Rev Genet 8: 884-896.

Chen X. 2005. MicroRNA biogenesis and function in plants. FEBS Lett 579: 5923-5931.

Chen X. 2009. Small RNAs and their roles in plant development. Annu Rev Cell Dev Biol 25: 21-44.

Chen ZJ, Tian L. 2007. Roles of dynamic and reversible histone acetylation in plant development and polyploidy. Biochim Biophys Acta 1769: 295-307.

Chen HM, Chen LT, Patel K, Li YH, Baulcombe DC, Wu SH. 2010. 22Nucleotide RNAs trigger secondary siRNA biogenesis in plants. Proc Natl Acad Sci 107: 15269-15274.

* Cheng X. 2014. Structural and functional coordination of DNA and histone methylation. Cold Spring Harb Perspect Biol 6: a018747.

Choi YH, Gehring M, Johnson L, Hannon M, Harada JJ, Goldberg RB, Jacobsen SE, Fischer RL. 2002. DEMETER, a DNA glycosylase domain protein, is required for endosperm gene imprinting and seed viability in Arabidopsis. Cell 110: 33-42.

Chuck G, Candela H, Hake S. 2009. Big impacts by small RNAs in plant development. Curr Opin Plant Biol 12: 81-86.

Cokus SJ, Feng SH, Zhang XY, Chen ZG, Merriman B, Haudenschild CD, Pradhan S, Nelson SF, Pellegrini M, Jacobsen SE. 2008. Shotgun bisulphite sequencing of the Arabidopsis genome reveals DNA methylation patterning. Nature 452: 215-219.

Cubas P, Vincent C, Coen E. 1999. An epigenetic mutation responsible for natural variation in floral symmetry. Nature 401: 157-161.

Cuperus JT, Carbonell A, Fahlgren N, Garcia-Ruiz H, Burke RT, Takeda A, Sullivan CM, Gilbert SD, Montgomery TA, Carrington JC. 2010. Unique functionality of 22-nt miRNAs in triggering RDR6-dependent siRNA biogenesis from target transcripts in Arabidopsis. Nat Struct Mol Biol 17: 997-1003.

Cuperus JT, Fahlgren N, Carrington JC. 2011. Evolution and functional diversification of MIRNA genes. Plant Cell 23: 431-442.

Czech B, Hannon GJ. 2011. Small RNA sorting: Matchmaking for Argonautes. Nat Rev Genet 12: 19-31.

Deal RB, Henikoff S. 2011. Histone variants and modifications in plant gene regulation. Curr Opin Plant Biol 14: 116-122.

Ding SW. 2010. RNA-based antiviral immunity. Nat Rev Immunol 10: 632-644.

Ding SW, Voinnet O. 2007. Antiviral immunity directed by small RNAs. Cell 130: 413-426.

Du T, Zamore PD. 2005. microPrimer: The biogenesis and function of microRNA. Development 132: 4645-4652.

* Dunoyer P, Melnyk CW, Molnar A, Slotkin RK. 2013. Plant mobile small RNAs. Cold Spring Harb Perspect Biol 5: 017897.

Durand S, Bouche N, Perez Strand E, Loudet O, Camilleri C. 2012. Rapid establishment of genetic incompatibility through natural epigenetic variation. Curr Biol 22: 326-331.

Earley KW, Shook MS, Brower-Toland B, Hicks L, Pikaard CS. 2007. In vitro specificities of Arabidopsis co-activator histone acetyltransferases: Implications for histone hyperacetylation in gene activation. Plant J 52: 615-626.

* Elgin SCR, Reuter G. 2013. Position effect variegation, heterochromatin formation, and gene silencing in Drosophila. Cold Spring Harb Perspect Biol 5: 017780 .
Elmayan T, Proux F, Vaucheret H. 2005. Arabidopsis RPA2: A genetic link among transcriptional gene silencing, DNA repair, and DNA replication. Curr Biol 15: 1919-1925.

Erhard KF Jr, Hollick JB. 2011. Paramutation: A process for acquiring trans-generational regulatory states. Curr Opin Plant Biol 14: 210216.

Feng S, Cokus SJ, Zhang X, Chen P-Y, Bostick M, Goll MG, Hetzel J, Jain J, Strauss SH, Halpern ME, et al. 2010. Conservation and divergence of methylation patterning in plants and animals. Proc Natl Acad Sci 107: 8689-8694.

Franco-Zorrilla JM, Valli A, Todesco M, Mateos I, Puga MI, Rubio-Somoza I, Leyva A, Weigel D, Garcia JA, Paz-Ares J. 2007. Target mimicry provides a new mechanism for regulation of microRNA activity. Nat Genet 39: 1033-1037.

Furner IJ, Matzke M. 2011. Methylation and demethylation of the Arabidopsis genome. Curr Opin Plant Biol 14: 137-141.

Gehring M, Reik W, Henikoff S. 2009. DNA demethylation by DNA repair. Trends Genet 25: 82-90.

Goll MG, Kirpekar F, Maggert KA, Yoder JA, Hsieh CL, Zhang XY, Golic KG, Jacobsen SE, Bestor TH. 2006. Methylation of tRNA(AsP) by the DNA methyltransferase homolog Dnmt2. Science 311: 395-398.

Graf P, Dolzblasz A, Wuerschum T, Lenhard M, Pfreundt U, Laux T. 2010. MGOUN1 encodes an Arabidopsis Type IB DNA Topoisomerase required in stem cell regulation and to maintain developmentally regulated gene silencing. Plant Cell 22: 716-728.

Grafi G, Zemach A, Pitto L. 2007. Methyl-CpG-binding domain (MBD) proteins in plants. Biochim Biophys Acta 1769: 287-294.

* Grossniklaus U, Paro R. 2014. Transcriptional silencing by Polycombgroup proteins. Cold Spring Harb Perspect Biol 6: a019331.

Haag JR, Pikaard CS. 2011. Multisubunit RNA polymerases IV and V: Purveyors of non-coding RNA for plant gene silencing. Nat Rev Mol Cell Biol 12: 483-492.

Haag J, Ream T, Marasco M, Nicora C, Norbeck A, Pasa-Tolic L, Pikaard C. 2012. In vitro transcription activities of Pol IV, Pol V, and RDR2 reveal coupling of Pol IV and RDR2 for dsRNA synthesis in plant RNA silencing. Mol Cell 48: 811-818.

Habu Y. 2010. Epigenetic silencing of endogenous repetitive sequences by MORPHEUS' MOLECULE1 in Arabidopsis thaliana. Epigenetics 5: $562-565$.

Havecker ER, Wallbridge LM, Hardcastle TJ, Bush MS, Kelly KA, Dunn RM, Schwach F, Doonan JH, Baulcombe DC. 2010. The Arabidopsis RNA-directed DNA methylation argonautes functionally diverge based on their expression and interaction with target loci. Plant Cell 22: $321-334$.

He XJ, Chen T, Zhu JK. 2011. Regulation and function of DNA methylation in plants and animals. Cell Res 21: 442-465.

Heitz E. 1929. Heterochromatin, Chromocentren, Chromomeren. (Vorlaufige Mitteilung.) Berichte der Deutschen Botanischen Gesellschaft 47: 274-284.

* Henikoff S, Smith MM. 2014. Histone variants and epigenetics. Cold Spring Harb Perspect Biol doi: 10.1101/cshperspect.a019364.

Herr AJ. 2005. Pathways through the small RNA world of plants. FEBS Lett 579: 5879-5888.

Hoffer P, Ivashuta S, Pontes O, Vitins A, Pikaard C, Mroczka A, Wagner N, Voelker T. 2011. Posttranscriptional gene silencing in nuclei. Proc Natl Acad Sci 108: 409-414.

Houben A, Demidov D, Caperta AD, Karimi R, Agueci F, Vlasenko L. 2007. Phosphorylation of histone H3 in plants-A dynamic affair. Biochim Biophys Acta 1769: 308-315.

Ikeda Y, Kinoshita Y, Susaki D, Ikeda Y, Iwano M, Takayama S, Higashiyama T, Kakutani T, Kinoshita T. 2011. HMG domain containing SSRP1 is required for DNA demethylation and genomic imprinting in Arabidopsis. Dev Cell 21: 589-596.

Ingouff M, Berger F. 2010. Histone3 variants in plants. Chromosoma 119: $27-33$.

Jackson S, Chen ZJ. 2010. Genomic and expression plasticity of polyploidy. Curr Opin Plant Biol 13: 153-159. 
Jacob Y, Stroud H, LeBlanc C, Feng S, Zhuo L, Caro E, Hassel C, Gutierrez C, Michaels SD, Jacobsen SE. 2010. Regulation of heterochromatic DNA replication by histone H3 lysine 27 methyltransferases. Nature 466: 987-991.

Jerzmanowski A. 2007. SWI/SNF chromatin remodeling and linker histones in plants. Biochim Biophys Acta 1769: 330-345.

Jones-Rhoades MW, Bartel DP, Bartel B. 2006. MicroRNAS and their regulatory roles in plants. Annu Rev Plant Biol 57: 19-53.

Jordan ND, West JP, Bottley A, Sheikh M, Furner I. 2007. Transcript profiling of the hypomethylated hog1 mutant of Arabidopsis. Plant Mol Biol 65: 571-586.

Jorgensen RA, Doetsch N, Muller A, Que Q, Gendler K, Napoli CA. 2006. A paragenetic perspective on integration of RNA silencing into the epigenome and its role in the biology of higher plants. Cold Spring Harb Symp Quant Biol 71: 481-485.

Joshua-Tor L. 2006. The Argonautes. Cold Spring Harb Symp Quant Biol 71: $67-72$.

Kapoor A, Agarwal M, Andreucci A, Zheng X, Gong Z, Hasegawa PM, Bressan RA, Zhu JK. 2005. Mutations in a conserved replication protein suppress transcriptional gene silencing in a DNA-methylation-independent manner in Arabidopsis. Curr Biol 15: 19121918.

Khraiwesh B, Zhu JK, Zhu J. 2012 Role of miRNAs and siRNAs in bioitic and abiotic stress responses of plants. Biochim Biophys Acta 1819: $137-148$

Kidner CA, Martienssen RA. 2005. The developmental role of microRNA in plants. Curr Opin Plant Biol 8: 38-44.

Kim JM, To TK, Seki M. 2012. An epigenetic integrator: New insights into genome regulation, environmental stress responses and developmental controls by HISTONE DEACETYLASE 6. Plant Cell Physiol 53: 794-800.

* Kingston RE, Tamkun JW. 2014. Transcriptional regulation by trithoraxgroup proteins. Cold Spring Harb Perspect Biol 6: a019349.

Klattenhoff C, Theurkauf W. 2008. Biogenesis and germline functions of piRNAs. Development 135: 3-9.

Koehler C, Hennig L. 2010. Regulation of cell identity by plant Polycomb and trithorax group proteins. Curr Opin Genet Dev 20: 541547.

Kumar SV, Wigge PA. 2010. H2A.Z-containing nucleosomes mediate the thermosensory response in Arabidopsis. Cell 140: 136-147.

Lahmy S, Bies-Etheve N, Lagrange T. 2010. Plant-specific multisubunit RNA polymerase in gene silencing. Epigenetics 5: 4-8.

Lauria M, Rossi V. 2011. Epigenetic control of gene regulation in plants. Biochim Biophys Acta 1809: 369-378.

Law JA, Jacobsen SE. 2010. Establishing, maintaining and modifying DNA methylation patterns in plants and animals. Nat Rev Genet 11: 204-220.

Law JA, Vashisht AA, Wohlschlegel JA, Jacobsen SE. 2011. SHH1, a homeodomain protein required for DNA methylation, as well as RDR2, RDM4, and chromatin remodeling factors, associate with RNA polymerase IV. PLoS Genet 7: e1002195.

Layat E, Saez-Vasquez J, Tourmente S. 2012. Regulation of Pol I-transcribed 45S rDNA and Pol III-transcribed 5S rDNA in Arabidopsis. Plant Cell Physiol 53: 267-276.

* Li E, Zhang Y. 2014. DNA methylation in mammals. Cold Spring Harb Perspect Biol 6: a019133.

Lisch D. 2009. Epigenetic regulation of transposable elements in plants. Annu Rev Plant Biol 60: 43-66.

Lister R, O'Malley RC, Tonti-Filippini J, Gregory BD, Berry CC, Millar AH, Ecker JR. 2008. Highly integrated single-base resolution maps of the epigenome in Arabidopsis. Cell 133: 523-536.

Liu C, Lu F, Cui X, Cao X. 2010. Histone methylation in higher plants. Annu Rev Plant Biol 61: 395-420.

Luo J, Hall BD. 2007. A multistep process gave rise to RNA polymerase IV of land plants. J Mol Evol 64: 101-112.
Magori S, Citovsky V. 2011. Epigenetic control of Agrobacterium T-DNA integration. Biochim Biophys Acta 1809: 388-394.

Manavella PA, Koenig D, Weigel D. 2012. Plant secondary siRNA production determined by microRNA-duplex structure. Proc Natl Acad Sci 109: $2461-2466$

* Marmorstein R, Zhou M-M. 2014. Writers and readers of histone acetylation: Structure, mechanism and inhibition. Cold Spring Harb Perspect Biol 6: a018762.

* Martienssen R, Moazed D. 2014. RNAi and heterochromatin assembly. Cold Spring Harb Perspect Biol doi: 10.1101/cshperspect.a019323.

Martínez-Macías M, Qian W, Miki D, Pontes O, Liu Y, Tang K, Liu R, Morales-Ruiz T, Ariza R, Roldán-Arjona T, et al. 2012. A DNA $3^{\prime}$ phosphatase functions in active DNA demethylation in Arabidopsis. Mol Cell 45: 357-370.

Matzke MA, Matzke AJM. 2004. Planting the seeds of a new paradigm. PloS Biol 2: 582-586.

Matzke M, Kanno T, Daxinger L, Huettel B, Matzke AJ. 2009. RNAmediated chromatin-based silencing in plants. Curr Opin Cell Biol 21: 367-376.

McClintock B. 1950. The origin and behavior of mutable loci in maize. Proc Natl Acad Sci 36: 344-355.

Mette MF, Aufsatz W, van der Winden J, Matzke MA, Matzke AJ. 2000. Transcriptional silencing and promoter methylation triggered by double-stranded RNA. EMBO J 19: 5194-5201.

Meyer P. 2011. DNA methylation systems and targets in plants. FEBS Lett 585: 2008-2015.

Miguel C, Marum L. 2011. An epigenetic view of plant cells cultured in vitro: Somaclonal variation and beyond. J Exp Bot 62: 37133725.

Mirouze M, Paszkowski J. 2011. Epigenetic contribution to stress adaptation in plants. Curr Opin Plant Biol 14: 267-274.

Montgomery TA, Howell MD, Cuperus JT, Li D, Hansen JE, Alexander AL, Chapman EJ, Fahlgren N, Allen E, Carrington JC. 2008. Specificity of ARGONAUTE7-miR390 interaction and dual functionality in TAS3 trans-acting siRNA formation. Cell 133: 128-141.

Mosher RA, Melnyk CW, Kelly KA, Dunn RM, Studholme DJ, Baulcombe DC. 2009. Uniparental expression of PolIV-dependent siRNAs in developing endosperm of Arabidopsis. Nature 460: 283-286.

Niehrs C. 2009. Active DNA demethylation and DNA repair. Differentiation 77: $1-11$.

Ohno Y, Narangajavana J, Yamamoto A, Hattori T, Kagaya Y, Paszkowski J, Gruissem W, Hennig L, Takeda S. 2011. Ectopic gene expression and organogenesis in Arabidopsis mutants missing BRU1 required for genome maintenance. Genetics 189: 83-95.

Okamura K, Hagen JW, Duan H, Tyler DM, Lai EC. 2007. The mirtron pathway generates microRNA-class regulatory RNAs in Drosophila. Cell 130: 89-100.

Ortega-Galisteo AP, Morales-Ruiz T, Ariza RR, Roldan-Arjona T. 2008. Arabidopsis DEMETER-LIKE proteins DML2 and DML3 are required for appropriate distribution of DNA methylation marks. Plant Mol Biol 67: 671-681.

Ossowski S, Schneeberger K, Lucas-Lledo JI, Warthmann N, Clark RM, Shaw RG, Weigel D, Lynch M. 2010. The rate and molecular spectrum of spontaneous mutations in Arabidopsis thaliana. Science 327: 92-94.

Pandey R, Muller A, Napoli CA, Selinger DA, Pikaard CS, Richards EJ, Bender J, Mount DW, Jorgensen RA. 2002. Analysis of histone acetyltransferase and histone deacetylase families of Arabidopsis thaliana suggests functional diversification of chromatin modification among multicellular eukaryotes. Nucleic Acids Res 30: 5036-5055.

Paszkowski J, Grossniklaus U. 2011. Selected aspects of transgenerational epigenetic inheritance and resetting in plants. Curr Opin Plant Biol 14: 195-203.

Pecinka A, Mittelsten Scheid O. 2012. Stress-induced chromatin changes: A critical view on their heritability. Plant Cell Physiol 53: 801-808.

Pedersen DS, Grasser KD. 2010. The role of chromosomal HMGB proteins in plants. Biochim Biophys Acta 1799: 171-174. 


\section{C.S. Pikaard and O. Mittelsten Scheid}

Pillai RS, Chuma S. 2012. piRNAs and their involvement in male germline development in mice. Dev Growth Differ 54: 78-92.

Poethig RS. 2009. Small RNAs and developmental timing in plants. Curr Opin Genet Dev 19: 374-378.

Poethig RS, Peragine A, Yoshikawa M, Hunter C, Willmann M, Wu G. 2006. The function of RNAi in plant development. Cold Spring Harb Symp Quant Biol 71: 165-170.

Pontvianne F, Blevins T, Pikaard CS. 2010. Arabidopsis histone lysine methyltransferases. Adv Bot Res 53: 1-22.

Preuss S, Pikaard CS. 2007. RRNA gene silencing and nucleolar dominance: Insights into a chromosome-scale epigenetic on/off switch. Biochim Biophys Acta 1769: 383-392.

Preuss SB, Costa-Nunes P, Tucker S, Pontes O, Lawrence RJ, Mosher R, Kasschau KD, Carrington JC, Baulcombe DC, Viegas W, et al. 2008. Multimegabase silencing in nucleolar dominance involves siRNA-directed DNA methylation and specific methylcytosine-binding proteins. Mol Cell 32: 673-684.

Raissig MT, Baroux C, Grossniklaus U. 2011. Regulation and flexibility of genomic imprinting during seed development. Plant Cell 23: 1626.

Ream TS, Haag JR, Wierzbicki AT, Nicora CD, Norbeck AD, Zhu JK, Hagen G, Guilfoyle TJ, Pasa-Tolic L, Pikaard CS. 2009. Subunit compositions of the RNA-silencing enzymes Pol IV and Pol V reveal their origins as specialized forms of RNA polymerase II. Mol Cell 33: 192203.

Reinders J, Paszkowski J. 2009. Unlocking the Arabidopsis epigenome. Epigenetics 4: 557-563.

Richards EJ. 2011. Natural epigenetic variation in plant species: A view from the field. Curr Opin Plant Biol 14: 204-209.

Rocha PS, Sheikh M, Melchiorre R, Fagard M, Boutet S, Loach R, Moffatt B, Wagner C, Vaucheret H, Furner I. 2005. The Arabidopsis HOMOLOGY-DEPENDENT GENE SILENCING1 gene codes for an S-adenosyl-L-homocysteine hydrolase required for DNA methylation-dependent gene silencing. Plant Cell 17: 404-417.

Roudier F, Teixeira FK, Colot V. 2009. Chromatin indexing in Arabidopsis: An epigenomic tale of tails and more. Trends Genet 25: 511-517.

Roudier F, Ahmed I, Berard C, Sarazin A, Mary-Huard T, Cortijo S, Bouyer D, Caillieux E, Duvernois-Berthet E, Al-Shikhley L, et al. 2011. Integrative epigenomic mapping defines four main chromatin states in Arabidopsis. EMBO J 30: 1928-1938.

Roux F, Colome-Tatche M, Edelist C, Wardenaar R, Guerche P, Hospital F, Colot V, Jansen RC. 2011. Genome-wide epigenetic perturbation jump-starts patterns of heritable variation found in nature. Genetics 188: $1015-1017$.

Rubio-Somoza I, Weigel D. 2011. MicroRNA networks and developmental plasticity in plants. Trends Plant Sci 16: 258-264.

Ruiz-Ferrer V, Voinnet O. 2009. Roles of plant small RNAs in biotic stress responses. Annu Rev Plant Biol 60: 485-510.

Rymarquis LA, Souret FF, Green PJ. 2011. Evidence that XRN4, an Arabidopsis homolog of exoribonuclease XRN1, preferentially impacts transcripts with certain sequences or in particular functional categories. RNA 17: 501-511.

Sang Y, Silva-Ortega CO, Wu S, Yamaguchi N, Wu MF, Pfluger J, Gillmor CS, Gallagher KL, Wagner D. 2012 Mutations in two non-canonical Arabidopsis SWI2/SNF2 chromatin remodeling ATPases cause embryogenesis and stem cell maintenance defects. Plant J 72: 1000-1014.

Schmitz RJ, Schultz MD, Lewsey MG, O’Malley RC, Urich MA, Libiger O, Schork NJ, Ecker JR. 2011. Transgenerational epigenetic instability is a source of novel methylation variants. Science 334: 369-373.

Schoft VK, Chumak N, Choi Y, Hannon M, Garcia-Aguilar M, Machlicova A, Slusarz L, Mosiolek M, Park J-S, Park GT, et al. 2011. Function of the DEMETER DNA glycosylase in the Arabidopsis thaliana male gametophyte. Proc Natl Acad Sci 108: 8042-8047.

Senda M, Masuta C, Ohnishi S, Goto K, Kasai A, Sano T, Hong J-S, MacFarlane S. 2004. Patterning of virus-infected Glycine max seed coat is associated with suppression of endogenous silencing of chalcone synthase genes. Plant Cell 16: 807-818.
Senthil-Kumar M, Mysore KS. 2011. New dimensions for VIGS in plant functional genomics. Trends Plant Sci 16: 656-665.

Servet C, Conde e Silva N, Zhou D-X. 2010. Histone acetyltransferase AtGCN5/HAG1 is a versatile regulator of developmental and inducible gene expression in Arabidopsis. Mol Plant 3: 670-677.

* Seto E, Yoshida M. 2014. Erasers of histone acetylation: The histone deacetylase enzymes. Cold Spring Harb Perspect Biol 6: a018713.

Shabalina SA, Koonin EV. 2008. Origins and evolution of eukaryotic RNA interference. Trends Ecol Evol 23: 578-587.

* Shi YG, Tsukada Y. 2013. The discovery of histone demethylases. Cold Spring Harb Perspect Biol 5: 017947.

Slotkin RK, Vaughn M, Borges F, Tanurdzic M, Becker JD, Feijo JA, Martienssen RA. 2009. Epigenetic reprogramming and small RNA silencing of transposable elements in pollen. Cell 136: 461-472.

Soppe WJJ, Jacobsen SE, Alonso-Blanco C, Jackson JP, Kakutani T, Koornneef M, Peeters AJM. 2000. The late flowering phenotype of fwa mutants is caused by gain-of-function epigenetic alleles of a homeodomain gene. Mol Cell 6: 791-802.

Springer NM, Kaeppler SM. 2005. Evolutionary divergence of monocot and dicot methyl-CpG-binding domain proteins. Plant Physiol 138: $92-104$.

Tan EH, Blevins T, Ream T, Pikaard C. 2012. Functional consequences of subunit diversity in RNA polymerases II and V. Cell Rep 1: 208-214.

Teixeira FK, Heredia F, Sarazin A, Roudier F, Boccara M, Ciaudo C, Cruaud C, Poulain J, Berdasco M, Fraga MF, et al. 2009. A role for RNAi in the selective correction of DNA methylation defects. Science 323: $1600-1604$.

Tucker SL, Reece J, Ream TS, Pikaard CS. 2010. Evolutionary history of plant multisubunit RNA polymerases IV and V: Subunit origins via genome-wide and segmental gene duplications, retrotransposition, and lineage-specific subfunctionalization. Cold Spring Harb Symp Quant Biol 75: 285-297.

Vaucheret H. 2008. Plant ARGONAUTES. Trends Plant Sci 13: 350-358.

Vazquez F, Legrand S, Windels D. 2010. The biosynthetic pathways and biological scopes of plant small RNAs. Trends Plant Sci 15: 337-345.

Verdel A, Vavasseur A, Le Gorrec M, Touat-Todeschini L. 2009. Common themes in siRNA-mediated epigenetic silencing pathways. Int J Dev Biol 53: 245-257.

Voinnet O. 2009. Origin, biogenesis, and activity of plant microRNAs. Cell 136: 669-687.

Voinnet O, Vain P, Angell S, Baulcombe DC. 1998. Systemic spread of sequence-specific transgene RNA degradation in plants is initiated by localized introduction of ectopic promoterless DNA. Cell 95: 177187.

Wassenegger M. 2002. Gene silencing. Int Rev Cytol 219: 61-113.

Wassenegger M, Krczal G. 2006. Nomenclature and functions of RNAdirected RNA polymerases. Trends Plant Sci 11: 142-151.

Wassenegger M, Heimes S, Riedel L, Sanger HL. 1994. RNA-directed de novo methylation of genomic sequences in plants. Cell 76: 567-576.

Westholm JO, Lai EC. 2011. Mirtrons: MicroRNA biogenesis via splicing. Biochimie 93: 1897-1904.

Wierzbicki AT, Haag JR, Pikaard CS. 2008. Noncoding transcription by RNA polymerase Pol IVb/Pol V mediates transcriptional silencing of overlapping and adjacent genes. Cell 135: 635-648.

Wierzbicki AT, Ream TS, Haag JR, Pikaard CS. 2009. RNA polymerase $\mathrm{V}$ transcription guides ARGONAUTE4 to chromatin. Nat Genet 41: $630-634$.

Woo HR, Pontes O, Pikaard CS, Richards EJ. 2007. VIM1, a methylcytosine-binding protein required for centromeric heterochromatinization. Genes Dev 21: 267-277.

Woo HR, Dittmer TA, Richards EJ. 2008. Three SRA-domain methylcytosine-binding proteins cooperate to maintain global CpG methylation and epigenetic silencing in Arabidopsis. PLoS Genet 4: e1000156.

Xiao WY, Gehring M, Choi Y, Margossian L, Pu H, Harada JJ, Goldberg RB, Pennell RI, Fischer RL. 2003. Imprinting of the MEA Polycomb 
gene is controlled by antagonism between MET1 methyltransferase and DME glycosylase. Dev Cell 5: 891-901.

Xie Z, Qi X. 2008. Diverse small RNA-directed silencing pathways in plants. Biochim Biophys Acta 1779: 720-724.

Yuan L, Yang X, Makaroff CA. 2011. Plant cohesins, common themes and unique roles. Curr Prot Pept Sci 12: 93-104.

Zaratiegui M, Irvine DV, Martienssen RA. 2007. Noncoding RNAs and gene silencing. Cell 128: 763-776.

Zemach A, Kim MY, Hsieh PH, Coleman-Derr D, Eshed-Williams L, Thao K, Harmer SL, Zilberman D. 2013. The Arabidopsis nucleosome remodeler DDM1 allows DNA methyltransferases to access H1-containing heterochromatin. Cell 153: 193-205.

* Zhao Y, Garcia BA. 2014. Comprehensive catalog of currently documented histone modifications. Cold Spring Harb Perspect Biol doi: 10.1101/ cshperspect.a025064.

Zhang H, Zhu JK. 2011. RNA-directed DNA methylation. Curr Opin Plant Biol 14: 142-147.

Zhang X, Yazaki J, Sundaresan A, Cokus S, Chan SW, Chen H, Henderson IR, Shinn P, Pellegrini M, Jacobsen SE, et al. 2006. Genome-wide highresolution mapping and functional analysis of DNA methylation in Arabidopsis. Cell 126: 1189-1201.

Zheng X, Pontes O, Zhu J, Miki D, Zhang F, Li W-X, Iida K, Kapoor A, Pikaard CS, Zhu J-K. 2008. ROS3 is an RNA-binding protein required for DNA demethylation in Arabidopsis. Nature 455: 1259-1262.

Zheng B, Wang Z, Li S, Yu B, Liu JY, Chen X. 2009. Intergenic transcription by RNA polymerase II coordinates Pol IV and Pol V in siRNAdirected transcriptional gene silencing in Arabidopsis. Genes Dev 23: $2850-2860$.

Zhu H, Hu F, Wang R, Zhou X, Sze SH, Liou LW, Barefoot A, Dickman M, Zhang X. 2011a. Arabidopsis Argonaute10 specifically sequesters miR166/165 to regulate shoot apical meristem development. Cell 145: $242-256$.

Zhu Y, Dong AW, Shen WH. 2011b. Histone variants and chromatin assembly in plant abiotic stress response. Biochim Biophys Acta 1819: 343-348.

Zhu Y, Rowley MJ, Bohmdorfer G, Wierzbicki AT. 2012. A SWI/SNF chromatin-remodeling complex acts in noncoding RNA-mediated transcriptional silencing. Mol Cell 49: 298-309.

Zilberman D, Gehring M, Tran RK, Ballinger T, Henikoff S. 2007. Genome-wide analysis of Arabidopsis thaliana DNA methylation uncov- ers an interdependence between methylation and transcription. Nat Genet 39: 61-69.

Zilberman D, Coleman-Derr D, Ballinger T, Henikoff S. 2008. Histone H2A.Z and DNA methylation are mutually antagonistic chromatin marks. Nature 456: 125-129.

* Zoghbi H, Beaudet A. 2014. Epigenetics and human disease. Cold Spring Harb Perspect Biol doi: 10.1101/cshperspect.a019497.

\section{WWW RESOURCES}

http://www.arabidopsis.leeds.ac.uk/act/coexpanalyser.php Arabidopsis coexpression mining

http://www.arabidopsis.org/index.jsp TAIR

http://asrp.cgrb.oregonstate.edu Arabidopsis small RNA

http://bbc.botany.utoronto.ca/efp/cgi-bin/efpWeb.cgi Gene expression in Arabidopsis

http://www.chromdb.org Chromatin genes

http://www.cymate.org/ Bisulfite sequence analysis

http://epigara.biologie.ens.fr/cgi-bin/gbrowse/a2e/ Arabidopsis epigenetics EPIGARA

http://epigenome.rutgers.edu/cgi-bin/gb2/gbrowse/Histone_modi fications Arabidopsis histone modifications Rutgers

http://www.erapg.org/publicpage.m?key=everyone\&trail=/everyone European plant genomic research

https://www.genevestigator.com/gv/ Gene expression in several organisms

http://genomes.mcdb.ucla.edu/AthBSseq/ Arabidopsis methylome of silencing mutants

http://katahdin.mssm.edu/kismeth/revpage.pl Bisulfite sequence analysis

https://www.mcdb.ucla.edu/Research/Jacobsen/LabWebSite/P_Epi genomicsData.shtml Arabidopsis histone modifications UCLA

http://mpss.udel.edu MPSS (Massively parallel signature sequencing)

http://neomorph.salk.edu/epigenome/epigenome.html Arabidopsis epigenome

https://www.plant-epigenome.org EPIC (Epigenomics of Plants International Consortium)

http://signal.salk.edu/cgi-bin/methylome Arabidopsis methylome

http://1001genomes.org Arabidopsis genetic variation 


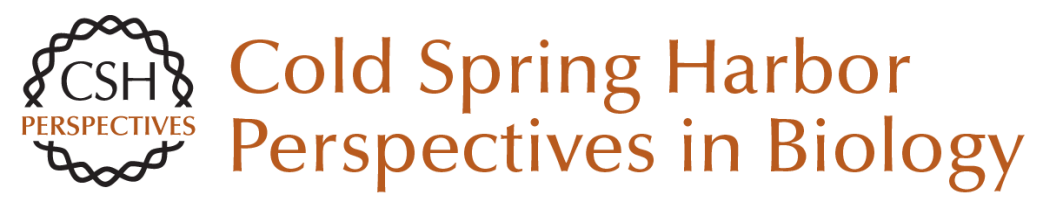

\title{
Epigenetic Regulation in Plants
}

\author{
Craig S. Pikaard and Ortrun Mittelsten Scheid
}

Cold Spring Harb Perspect Biol 2014; doi: 10.1101/cshperspect.a019315

\section{Subject Collection Epigenetics}

Metabolic Signaling to Chromatin Shelley L. Berger and Paolo Sassone-Corsi

Histone and DNA Modifications as Regulators of Neuronal Development and Function Stavros Lomvardas and Tom Maniatis

Histone Modifications and Cancer James E. Audia and Robert M. Campbell

Epigenetics and Human Disease Huda Y. Zoghbi and Arthur L. Beaudet

Induced Pluripotency and Epigenetic Reprogramming Konrad Hochedlinger and Rudolf Jaenisch

Long-Range Chromatin Interactions Job Dekker and Tom Misteli

RNAi and Heterochromatin Assembly Robert Martienssen and Danesh Moazed

Dosage Compensation in Drosophila John C. Lucchesi and Mitzi I. Kuroda
Epigenetic Determinants of Cancer Stephen B. Baylin and Peter A. Jones

Maintenance of Epigenetic Information Geneviève Almouzni and Howard Cedar

A Structural Perspective on Readout of Epigenetic Histone and DNA Methylation Marks Dinshaw J. Patel

The Necessity of Chromatin: A View in

Perspective Vincenzo Pirrotta

Germline and Pluripotent Stem Cells Wolf Reik and M. Azim Surani

Comprehensive Catalog of Currently Documented Histone Modifications Yingming Zhao and Benjamin A. Garcia

Epigenetic Regulation of Chromatin States in Schizosaccharomyces pombe Robin C. Allshire and Karl Ekwall

Histone Variants and Epigenetics Steven Henikoff and M. Mitchell Smith

For additional articles in this collection, see http://cshperspectives.cshlp.org/cgi/collection/

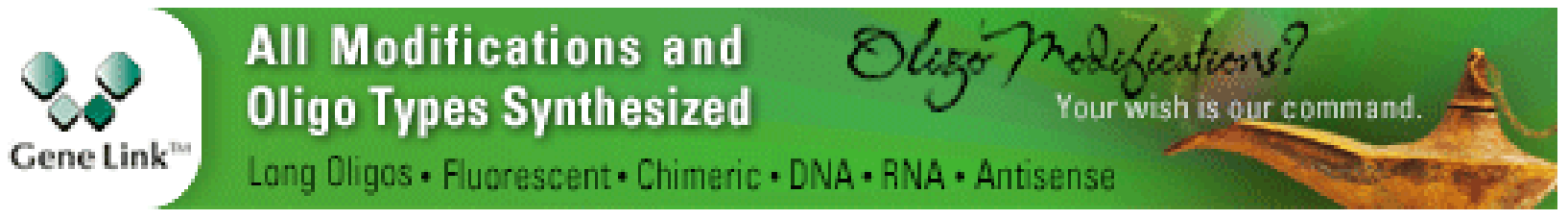

Copyright (C 2014 Cold Spring Harbor Laboratory Press; all rights reserved 
For additional articles in this collection, see http://cshperspectives.cshlp.org/cgi/collection/

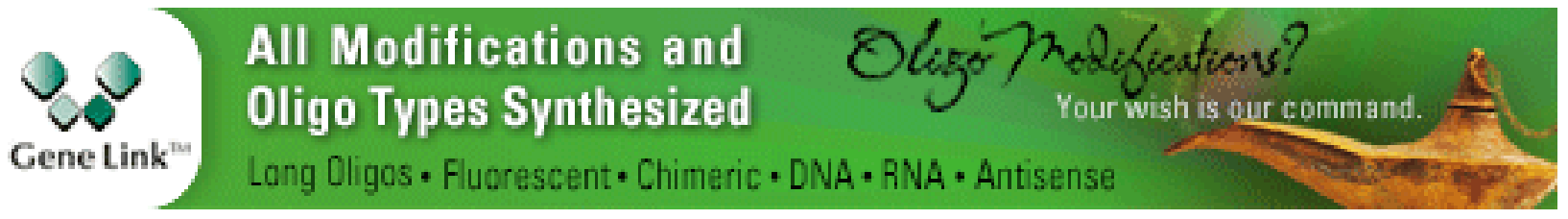

Copyright @ 2014 Cold Spring Harbor Laboratory Press; all rights reserved 